Portland State University

PDXScholar

$11-1-1989$

\title{
The Effect of Media on the Listening Comprehension Scores of Intermediate ESL Students
}

Marian Tyson

Portland State University

Follow this and additional works at: https://pdxscholar.library.pdx.edu/open_access_etds

Part of the Applied Linguistics Commons, and the Bilingual, Multilingual, and Multicultural Education Commons

Let us know how access to this document benefits you.

\section{Recommended Citation}

Tyson, Marian, "The Effect of Media on the Listening Comprehension Scores of Intermediate ESL Students" (1989). Dissertations and Theses. Paper 3961.

https://doi.org/10.15760/etd.5843

This Thesis is brought to you for free and open access. It has been accepted for inclusion in Dissertations and Theses by an authorized administrator of PDXScholar. Please contact us if we can make this document more accessible: pdxscholar@pdx.edu. 
AN ABSTRACT OF THE THESIS OF Marian Tyson for the Master of Arts in TESOL presented November 1, 1989.

Title: The Effect of Media on the Listening Comprehension Scores of Intermediate ESL Students.

APPROVED BY THE MEMBERS OF THE THESIS COMMITTEE:

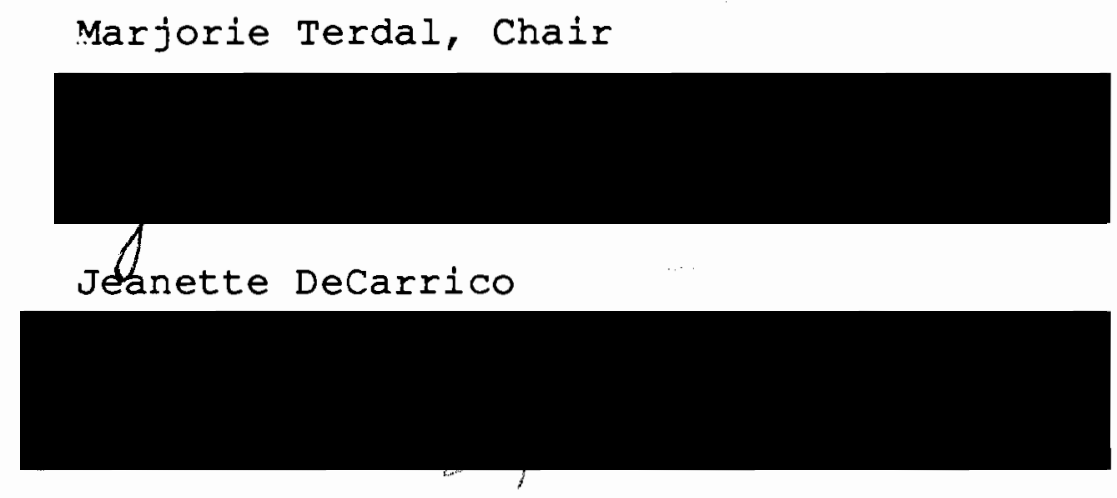

Devorah Lieberman

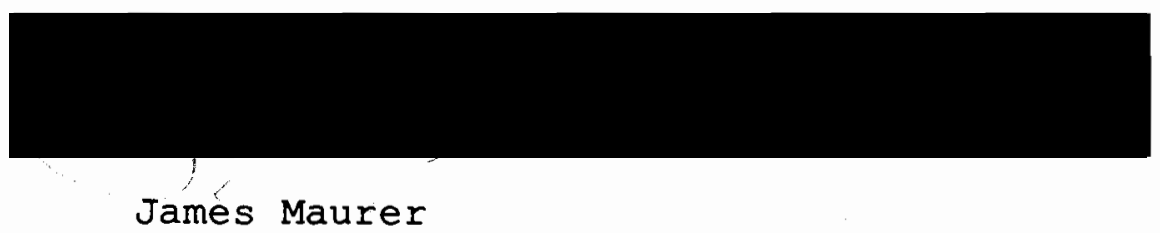

The use of videotapes has become widespread in ESI classes in recent years. The decline in cost of tapes and VCR equipment has assisted in the spread of this technology. These tapes are often used in listening comprehension classes 
and may replace or supplement the use of audiotapes. However, research has not established that the addition of the visual element, especially in the movie or TV type context of many videos, is an advantage to the language learner.

A total of seventy-six students participated in a listening comprehension recall exercise. Thirty-nine students viewed a videotape segment, and the remaining thirty-seven students listened to the audio portion of the same segment. Each group viewed or listened to the tape two times. Then the groups were given twenty minutes to write a recall. Each paper was scored for total idea units recalled, macropropositions, elaborations, and distortions.

The hypotheses posed were:

1. ESL students listening to an audiotape will score higher on an immediate recall protocol listening comprehension text than the students watching a videotape of the same material.

2) ESL students listening to an audiotape will have fewer elaborations on the immediate recall protocol than will students watching the videotape.

3) ESL students listening to an audiotape will have fewer distortions on the immediate recall protocol than will students watching the videotape.

4) ESL students listening to an audiotape will remember more macropropositions on the immediate recall protocol than will students watching the videotape.

5) ESL students listening to an audiotape will have immediate recall protocol scores which will correlate with their TOEFL (Test of English as a Foreign Language) or Michigan Test of English Language Proficiency scores. 
T-tests were used to compare the listening comprehension scores of the two groups. The video group generally outperformed the audio group recalling more idea units and macropropositions, and reporting fewer distortions of information. The audio group elaborated less than the video group; however, the data suggests that in this case, the audio group elaborated less than the video group because they understood less information. T-tests were also used to compare the composition of the groups tested. The tests show that there was a more normal distribution of students in the video group than the audio group. Also the scores of students at one institution differed significantly from those at other institutions. The fifth hypothesis was not tested due to the unavailability of TOEFL listening scores for the groups tested. 
THE EFFECT OF MEDIA ON THE LISTENING COMPREHENSION SCORES OF INTERMEDIATE ESL STUDENTS

\author{
by \\ MARIAN TYSON
}

A thesis submitted in partial fulfillment of the requirements for the degree of MASTER OF ARTS in TESOL 
TO THE OFFICE OF GRADUATE STUDIES:

The members of the Committee approve the thesis of Marian Tyson presented November 1, 1989.

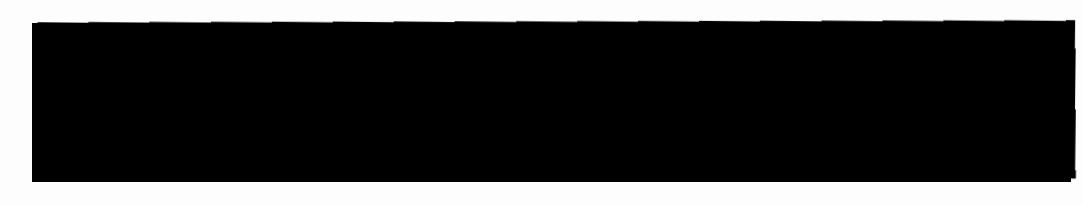

Marjorie Terdal, Chair

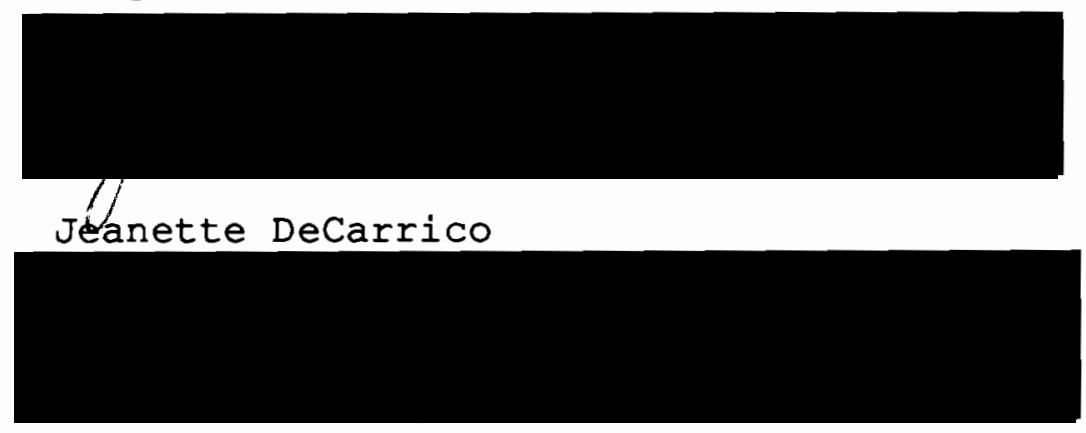

Devorah Lieberman

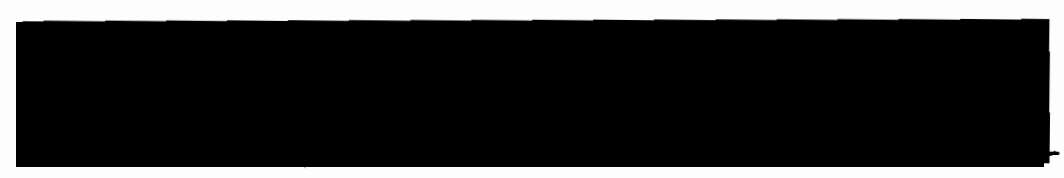

James Maurer

APPROVED :

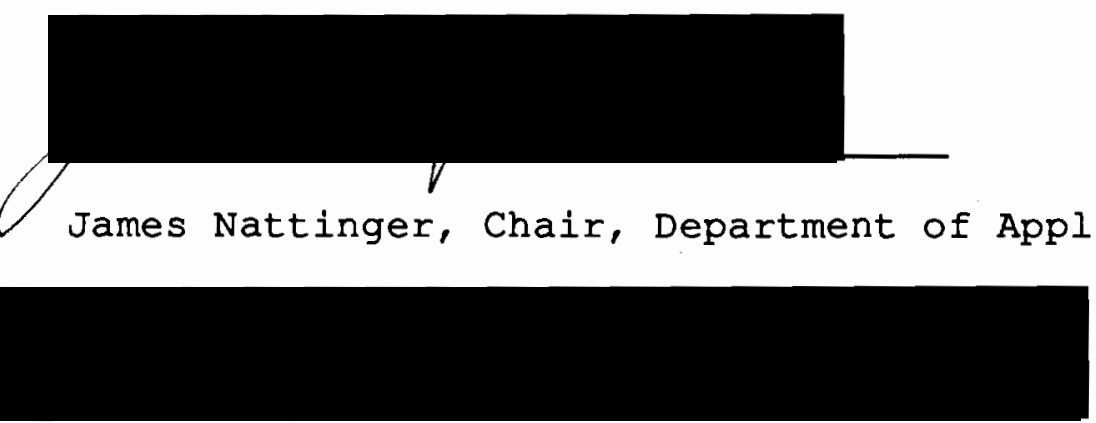

C. William Savery, Interim Vice Provost for Graduate Studies and Research 
TABLE OF CONTENTS

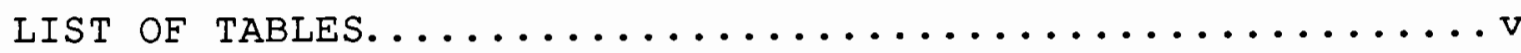

LIST OF FIGURES......................... vi

\section{CHAPTER}

I INTRODUCTION $\ldots \ldots \ldots \ldots \ldots \ldots \ldots \ldots \ldots$

Statement of Hypotheses..............4

I I REVIEW OF THE Literature.............. 8

Listening in $L 1 \ldots \ldots \ldots \ldots \ldots \ldots \ldots$

Listening in $2 . \ldots \ldots \ldots \ldots \ldots \ldots \ldots \ldots$

Testing Listening Comprehension ......... 13

Media and Listening Comprehension........ 15 Use of Audiotapes

Use of Visual Media

Use of Videotapes

Comparative Studies of Audio and Video in Listening Comprehension

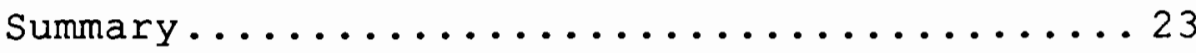

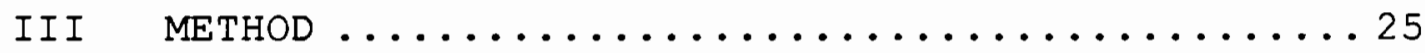

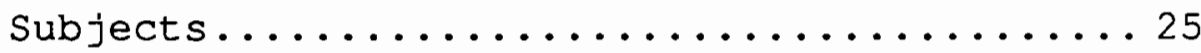

Instruments and Materials........... 27

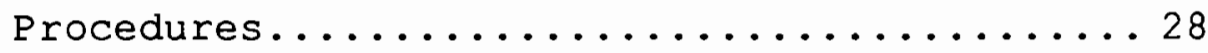

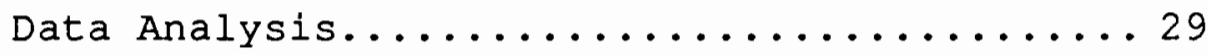

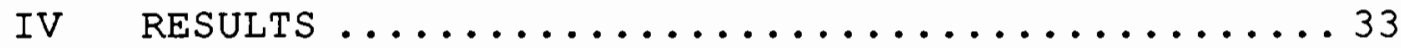

Results of Immediate Recall Protocol.......34

Comparison of Groups.................... 


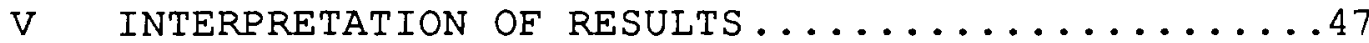
Interpretation of the

Immediate Recall Protocol Results......... 47

Interpretation of the Comparison of Groups.. 51

VI CONCLUSIONS AND RECOMMENDATIONS........... 54

Conclusions from study................ 57

Implications for Teaching.............. 58

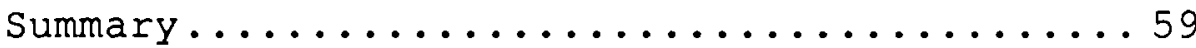

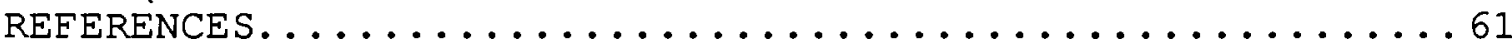

APPENDICES

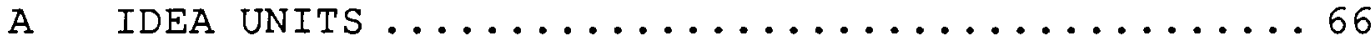

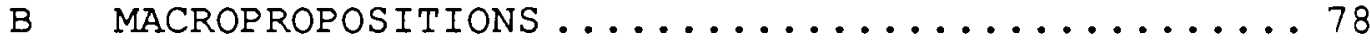

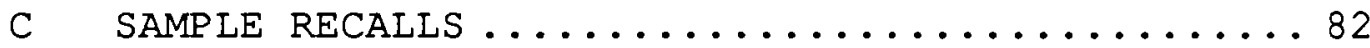


I Total Units Recorded ....................

I Recall of Total Idea Units................

III Recall of Macropropositions................ 35

IV Elaborations Reported...................

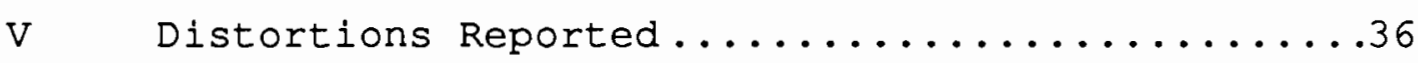

VI Mean and Standard Deviation of Total

Idea Units - Audio Groups................. 37

VII Mean and Standard Deviation of Total

Idea Units - Video Groups..............38

VIII Comparison of Al Audio Group with Other

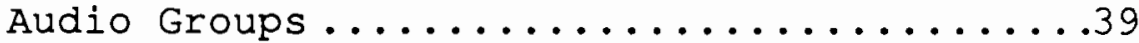

IX Comparison of A1 Video Group with other

Video Groups...................40 


\section{LIST OF FIGURES}

FIGURE

PAGE

1. Total Idea Units Recalled - Audio...........41

2. Total Idea Units Recalled - Video..........41

3. Macropropositions Recalled - Audio..........43

4. Macropropositions Recalled - Video..........43

5. Distortions Observed - Audio.............44

6. Distortions Observed - Video...............44

7. Elaborations Observed - Audio.............45

8. Elaborations Observed - Video.............45 
CHAPTER I

\section{INTRODUCTION}

Material for listening comprehension in second language classes can be presented through a variety of media. The use of video tapes in language learning classes has increased rapidly in recent years. Although much has been written on techniques for using video, little research had been done establishing video as a medium which is superior to audio or other media. This study compares the listening comprehension recall of intermediate ESL students using audio and video. Students enrolled in listening comprehension ESL classes at postsecondary institutions either listened to or watched a video. After a second playing of the tape, the students wrote an immediate recall protocol to measure their listening comprehension. The results were then tabulated to determine if there were any significant differences between the scores of the audio and video groups.

Prior to the 1980's, the role of listening comprehension in second language learning was viewed as the passive counterpart of speaking. Listening comprehension is now recognized as an active process (see, for example, Byrnes, 1984; James, 1986; Rivers, 1983; Widdowson, 1978). Widdowson (1978) defines listening as "the activity of recognizing what 
function sentences have in an interaction, what communicative value they take on as instances of use" (p. 60). Listeners are not passive recipients of information, but are participants in a communicative event. Although people usually listen to their native language without a great degree of conscious effort, numerous processing skills are being unconsciously utilized. Focusing on these skills can help language learners improve their listening comprehension skills (see, for example, Anderson \& Lynch, 1988; Richards, 1983; Ur, 1984).

One technique currently utilized as a method of improving the listening comprehension of language learners involves the use of videotapes. Many articles have been written in the current decade describing techniques for using video in language teaching (see, for example, Carr \& Duncan, 1987; Danahy, 1985; Svensson \& Bogarskola, 1985). Some advantages of video include: the use of authentic language; the presence of visual contextual clues to assist language learners in extracting meaning from conversations; and the option to pause and repeat segments of dialogue as needed (see, for example, Carr \& Duncan, 1987; Lonergan, 1984; Svensson \& Bogarskola, 1985).

However, little research has been done to support video as an effective medium for teaching listening comprehension in second language learning. What research has been done has yielded conflicting results. The various studies have not 
attempted to replicate earlier ones and are thus not truly comparable. Three researchers found no significant difference between the audio and visual modes (Wright, 1971; Stallings, 1971; and Durio \& Kildow, 1979). Two studies supported the hypothesis that students who watched a videotape of a dialogue or interview would score higher on a listening comprehension exam than those who listened only to the audio. Only one study used a videotape not specifically designed for language testing (Ortmeyer \& Goldstein, 1980). In this study, the students who listened only to the audio scored higher than those students who watched the video.

Criticisms or cautions about the use of video stem from the association of "watching movies" as a form of entertainment, rather than as a form of education (Lonergan, 1984). Some articles recommending the use of video stress the importance of lesson plans structured to elicit viewer interaction. This interaction can be achieved through the use of prepared exercises or class discussions related to the video viewed.

The effectiveness of video, especially commercial movies, in the language-learning classroom has not been supported by research studies (MacWilliam, 1986). As mentioned earlier, most research projects have used videotapes specially made for the purpose of testing. The one project that used a commercial video (Ortmeyer \& Goldstein, 1980) produced support for the hypothesis that 
students who listen to the audio portion will score higher on a listening comprehension test than students who watch the video. Audiotapes allow students to concentrate on the spoken language, without also having to process visual cues. In a video, there are many superfluous visual details that do not add to the understanding of the message. If the intent of the listening comprehension class is to improve students' abilities to process the spoken language, then research is needed to establish whether audio is a more effective medium than video, especially commercial video not specifically developed for language teaching.

\section{STATEMENT OF HYPOTHESES}

This study examines the differences between recall of information presented by either the audio or audio-visual media based on the following hypotheses:

1) ESL students listening to an audiotape will score higher on an immediate recall protocol listening comprehension test than will the students watching a videotape of the same material.

2) ESL students listening to an audiotape will have fewer elaborations on the immediate recall protocol than will students watching the videotape. 
3) ESL students listening to an audiotape will have fewer distortions on the immediate recall protocol than will students watching the videotape.

4) ESL students listening to an audiotape will remember more macropropositions on the immediate recall protocol than will students watching the videotape.

5) ESL students listening to an audiotape will have immediate recall protocol test scores with a high positive correlation to their TOEFL (Test of English as a Foreign Language) listening scores.

Support for the first hypothesis would show that students who listen to an audiotape recall more information units on a listening comprehension recall than those who watch and listen to the same videotape. The immediate recall protocol has been chosen as the test instrument since it does not limit students to recall of a few specific facts, as would a multiple-choice quiz, but rather allows them to record all units of information remembered. The second and third hypotheses state that ESL students receiving the audio treatment will have fewer elaborations and distortions than the students receiving the video treatment. Audiotapes limit the student to the processing of the audible linguistic input. Video, in providing a visual stimulus, might cause the student to include information in the recall not included 
In the test or distract the student and cause a higher rate of distortion in recall. Support for the fourth hypothesis would indicate that students listening to an audio tape are better able to determine the main points of a text than those who are also watching the video. Finally, a strong positive correlation between the scores of the audio group on the immediate recall protocol and their TOEFL scores would suggest the audio recall to be a reliable measure of listening comprehension skill.

Undeniably, video can provide visual contextual information to the spoken dialogue, but does some of this additional visual information inhibit the processing of linguistic information? Language learners process the spoken second language (L2) more slowly than native speakers. For some students, the combination of linguistic and visual information may be too much to process. First language studies have shown that when there is a conflict between processing information in the visual and linguistic modes, it is the linguistic mode than is ignored (Donaldson in MacWilliam, 1986). Ur (1984) states the problem with extraIinguistic clues is one of overload for the learner, who "has to work much harder at decoding than the native listener. . . and tries to interpret every detail. . ." (p. 21).

The presence of visual information cannot be assumed to be necessarily relevant to the linguistic message being conveyed, and the visual information may overload the 
learner. Students react to this overloading of information in a variety of ways. Some students shut out the visual information by closing their eyes in order to concentrate on the audible portion of the message. Other students reduce their attention to the spoken message and attempt to process the message by relying mainly on the visual clues. Another option, pursued by a few students, is to not bother with the dialogue at all, rather simply watch the "movie."

The subjects for this study were students in higher educational institutions. Much of the information they receive as college students will not be in the context of a visual element that reinforces the information conveyed (such as facts presented in a lecture). Lack of a visual element may not be a hindrance in some learning situations and these situations need to be clarified. support for these hypotheses will suggest that some language learners (such as those intermediate students included in this study) process some types of language (in this case a scripted educational video) more effectively without a visual element and that additional research is needed to determine the best uses of the audio and video media. 


\section{REVIEW OE THE LITERATURE}

The role of listening comprehension in language learning has varied according to the dominant approach for that period. The audiolingual approach viewed listening (comprehension) as the passive component of habit formation. speaking (production) was the active component. In the 1980 's, numerous researchers have presented analyses of listening as the active processing of many components of information (Anderson \& Lynch 1988; Byrnes, 1984; Richards, 1983; Rivers, 1983). Just as the role of listening comprehension has changed from that of habit formation in the audiolingual era to that of active language processing in the communicative era, the means of testing listening comprehension has also changed from recall of discrete points to a recall of more general information. The use of media has become more prominent and diversified; audiotapes have been sometimes supplemented and sometimes supplanted by videotapes. Although some research has been done on the use of audio and video tapes in listening comprehension, the results have often been conflicting. For the second language learner, listening is a complex, difficult task, requiring the synthesizing of many components. 
IISTENING IN LI

Native speakers usually listen to their language without much effort. Often the degree of effort depends on the listening task; listening to an academic lecture requires much more effort than watching and listening to a situation comedy on television, especially if later recall of the lecture is required on an examination. There are many different components involved in the listening process. Samuels (1984) includes the following factors in processing language; language facility; background knowledge and schema; metacognitive strategies (listening strategies); speech registers; kinesics; and motivation.

One component of language facility involves accuracy and automaticity, consisting of the listeners' ability to divide the speech stream into morpheme and syntactic units. Listeners need to chunk language correctly to identify the meaning. Richards (1983) illustrates with the following sentence: "I am informed that your appointment has been terminated," has been divided into "I am informed/that your appointment/has been terminated." If learners chunk the sentence as follows, "I am/informed that your/appointment has/been terminated," it will be difficult for them to extract the meaning. The listener also needs a knowledge of vocabulary and a knowledge of the variety of ways a word can be used. Native speakers can reduce the amount of effort needed to process the incoming information by anticipating 
what will be said. Sometimes the speaker need only anticipate the rest of a word or phrase. Ur (1984) points out that a native speaker who hears "He was in a towering. . ." will usually be able to predict "rage" as the next word. I2 learners lack the familiarity with various vocabulary usages necessary to reduce listening processing time.

Schema knowledge is an essential component of information processing. Hare and Devine (1983), using a passage about dolls in a study with first graders, found that topical knowledge correlated highly with listening comprehension scores. The researchers also found that topical interest did not correlate with topical knowledge. Although boys expressed the least interest in reading about dolls, those boys who scored high on the measure of topical knowledge also scored high on the measure of listening comprehension.

Listening strategies have to be developed in LI as well as in L2. An example of strategies is the listener's awareness of a breakdown in comprehension and how and when to request additional information or clarification. Children have improved their listening skills by being taught how to ask for clarification from the speaker (Cosgrove and Patterson, 1977; Ironsmith and Whitehurst, 1978.)

Other factors involved in listening involve the ability to understand a variety of speech registers and the ability to understand the nonverbal behavior of the speaker. 
Finally, the listener must be motivated enough to focus on the message of the speaker (Anderson, 1988; Samuels, 1984; Ur, 1984).

\section{LISTENING IN L2}

A variety of approaches to listening comprehension have been applied in the L2 classroom. Byrnes (1984) categorizes these approaches into three types. The linguistic approach is an analysis of how the listener arrives at a phrasal structural description based on the phonological, lexical, syntactic and semantic components of language. The conceptual approach examines how the listener assigns a conceptual structure to the linguistic input. The communicative approach explores the interaction between speaker and Iistener.

Another approach stresses the primacy of listening in language development. Children listen to and understand their native language before they begin to speak it. Their level of comprehension is greater than their level of production as they learn their native language. Krashen (1981) suggests that the language learners' environment should consist of " $i+1$ ". The term " $i+1$," from Krashen's theory of language acquisition, refers to the input the listener receives. According to Krashen, the optimal environment for language learning should include input which is one level above that which the learner is able to produce. 
Although learners are not able to produce language at the "i +1 " level, they are able to understand it through the use of context or other knowledge of the world. An example of $i+$ $1 "$ is caretaker speech. Adults may simplify language to talk to children, using structures and vocabulary that the children will understand, but not use in their own speech.

Numerous researchers have applied " $i+1$ " to advocate a silent period in language learning (Asher, 1981; Gary, 1979; Nord, 1981; Postovosky, 1981; Winitz, 1981). Each researcher stresses that an emphasis on speaking slows down the listening comprehension of the learner. Learners are cognitively overwhelmed when they are required to speak before achieving some basic facility in listening comprehension. The recommended length of the silent period varies among the researchers as do their research methods. Nord, using Russian language students, used a combination of listening to cassettes and reading. Asher developed the Total Physical Response method, requiring the students to act out the command that they hear. Winitz' students indicated language comprehension after listening to a particular word or phrase by marking a picture corresponding to that work or phrase. Postovosky used a synchronization of language materials and pictorial events. Each researcher compared the "silent period" group with a control group who immediately began production in the target language (L2). At the end of each experimental period, the delayed oral production group 
scored higher on a language proficiency test than the control group.

TESTING LISTENING COMPREHENSION

The testing of listening comprehension has followed the changes in the teaching focus of L2. During the audiolingual period, listening comprehension was often tested by means of dictation exercises. As language was viewed as a system of units, testing often focused on discrete points, whether in a dictation exercise or on a multiple-choice test. James (1986) points out that the Carroll-Sapon Modern Language Aptitude Test, Form $A$ (1959) and the Pimsleur Language Aptitude Battery (1966) included sections testing student ability to discriminate between spoken minimal pairs. Both of these tests were widely used during the era dominated by audiolingualism.

Even as the cognitive approach became more widespread, listening comprehension testing continued to consist of dictations and multiple-choice tests. However a transition began, and exercises reflected more authentic language used for communicative purposes.

In the current era of communicative competence, another shift in testing techniques is occurring. Many educators have been concerned that listening comprehension examinations too often test memory as well as comprehension of the utterance. Memory certainly is important. Call's (1985) 
research showed the importance of short-term memory as a component of listening comprehension. "Memory for syntax emerged as the best predictor of listening skill in the test battery" (p. 776). Students need to be able to recall what was talked about. However, too often listening comprehension is tested in a multiple-choice recall test. Students may not remember the specific items called for on the test. If they concentrate on the wrong information, they may have understood the main idea, but not remembered specific dates or names. Information focus is not a problem for L2 learners only. Many native speakers have experienced being introduced to someone at a social gathering, and have found themselves unable to recall the person's name a short time later. The person's occupation may be remembered, or other personal information, but not the name. Lack of recall of specific items can create a serous problem for someone who is trying to get a high score on some type of multiple-choice listening comprehension test.

The immediate recall protocol offers some relief to this situation. The students listen to a text in the target language and then write down in their native language everything that they can recall about the text. The papers are scored based on the number of idea units generated. As the research mentioned earlier has shown (Asher, 1981; Gary, 1979; Postovosky, 1981) students' receptive language skills exceed their productive skills. By using their native 
language, students may be able to describe concepts they understood in the L2, but could not express in that language. Unfortunately, most ESL teachers are ill-equipped to read the summaries written by the students in their native language. EEL classrooms in which all the students have the same native language would be better suited to utilize this method. A modified version of the protocol method is gaining widespread use. The modified method involves having the students recall the information in the L2 (Markham \& Latham, 1979; Markham, 1988). Some researchers appear to give equal weight to all propositions recorded by the students. James (1986), in a sample, lists the total number of idea units for the passage. Bernhardt and James (1987) weighted propositions determined to be main ideas more heavily than those determined to be supporting ideas.

\section{MEDIA AND LISTENING COMPREHENSION}

The use of audiotapes was a prominent feature of the audiolingual period. Now audiotapes are a much smaller part of the language learners' experience. In contrast, interest in the use of video is growing. Video is touted as a way to bring authentic language from a wide variety of speakers into the classroom. Proponents of video usage stress the importance of contextual clues in communication. Unfortunately very little empirical research has been done to substantiate these claims. Hartman (1961) in his review of 
the literature on single and multiple channel communication states, "a pictorial message is pregnant with meaning but this meaning is often ambiguous and subject to personal interpretation" (p. 256). He emphasizes that learning from mass media such as television, a producer of a large number of auditory and visual cues, is an extremely complex process. The following sections will summarize the applications of audio and audio-visual media and relevant research.

\section{Use of Audiotapes}

Very little recent information is available on the use of audio as a tool in listening comprehension. Audio may not be favored as a teaching tool because of its prominent role in drills with repetitions, substitutions and fill-ins when the audiolingual method was dominant in the 1960's. Students often spent long hours in a language laboratory, sometimes equipped with very outdated equipment. Byrnes (1982) is one of the few researchers to make a case for the use of audiotapes. She suggests using them to assist in acquisition of phonological and structural patterns. The use of audiocassettes is not limited to acquisition of sound patterns; they can also be used to present authentic dialogues. Tapes can be used to help the learner increase attention and memory span without being in the on-the-spot pressure situation of the classroom. Morley (1980) stresses that the lab specialist not only must know the technology of 
the equipment, but must also be aware of current theory and pedagogy.

Other researchers criticize audiotapes because of their lack of authenticity (James, 1984; Porter \& Roberts, 1987). One criticism is that tapes do not have any background noise. This may be true of some tapes, but others are specially made to include background noise (such as on an on-the-spot live news broadcast). While authentic background noise may be appropriate for advanced students, beginning students may be frustrated by such a distraction. Another criticism is that much of the language is spoken in slow, precise tones. On some tapes, the rate of speech is slower than for the average American speaker, but other tapes are authentic recordings from sources such as TV or radio.

In summary, little information is available on the use of audiotapes, whether in the area of theory or application. Since listening comprehension is now recognized as an active part of the communicative process, more research should be devoted to the applicability of audiotapes in assisting the learner to develop listening skills.

\section{Use of Visual Media}

In support of the visual element, widdowson (1978) states, "Listening . . is the receptive counterpart of saying and depends on the visual as well as the aural medium" (p. 60). Most of the current research in audio-visual 
media specifically refers to video. However, one important study on visual context clues used line drawings on an overhead projector to help listeners put the information in context (Mueller, 1980). The visual provided only information available from listening to the passage alone. There were three treatment groups. One group saw the drawings before listening to the passage, the other group saw the drawings after, and the third group saw no visuals. The dependent variable in this study was a free recall English summary of the passage listened to in German. Summaries were scored on the basis of the number of semantic propositions they contained. The passage was a taped interview of 300 words. The contextual visual was a line drawing showing the participants in the interview and their relationship to one another. Seeing the visual before the interview was the most effective treatment. It was hypothesized that the visual served as an advance organizer for the information received. The lower level students who saw the visual aids scored significantly higher than those who did not. There was no significant difference between the visual and nonvisual groups at a more advanced level.

\section{Use of Videotapes}

Many journal articles and teaching seminars advocate the use of video as an aid to listening comprehension. The following advantages of videotapes are mentioned by Svensson 
and Bogarskola (1985). Video shows facial expressions and gestures simultaneously. Authentic materials can be used, such as current and actual events. Since videotapes can be rewound and replayed, one suggested technique is playing a short scene several times, then between showings requesting feedback from learners. Students can be taught language structures, can describe what they have seen, or can break into pairs and have a discussion. Other techniques mentioned by Svensson and Bogarskola (1985) include: turning off the sound and allowing visual information only; allowing students to invent a commentary; stopping the tape to focus on a face or to ask students what's coming next; and asking students to compare, contrast, criticize, explain, or illustrate.

One of the strongest arguments for the use of video is that video provides nonverbal cues to communication. Dahl (1984) found the inability to interpret nonverbal cues inhibited the communicative ability of his German language students, and he developed a methodology to teach this aspect of communication.

Other researchers, while recognizing the benefits of video, warn of potential problems (Carr and Duncan, 1987; Lonergan, 1984; MacWilliam, 1986). Unfocused viewing does not develop either language or cultural proficiency. In a domestic setting, people watch TV for entertainment and relaxation; TV makes no demands. The teacher has to make sure that the same atmosphere does not develop in the 
classroom. There needs to be some form of interaction with the video.

MacWilliam (1986) is one of the few to address the problem that little or no research exists to support the effectiveness of video as a source of language input to the language learner. MacWilliam criticizes the English language teaching profession for tending "to eschew empirical research - . preferring instead to rely on the solipsism known as 'construct validity'" (p. 131). Macwilliam cites first language studies that discuss conflict between information presented in linguistic and visual modes to younger children. According to Donaldson (in MacWilliam, 1986) when there is a conflict between the two modes, the linguistic mode is ignored. More research is definitely needed to determine if the VCR revolution is a beneficial trend for the L2 learner.

Comparative studies of Audio and Videe In Iistening Comprehension

Although numerous research projects in both L1 and L2 have been conducted to compare the effect of the medium on the listening comprehension of students, there have been no consistent findings in the research that has been done. Lack of consistency is probably due in part to the difference in the research design of each of the studies. No one seems to have tried to exactly replicate exactly an earlier study either to add support or to question an earlier hypothesis. 
Those researchers who found no significant difference between the audio and visual modes include: Wright, 1971; Stallings, 1971; and Durio and Kildow, 1979. Wright tested ESI students. Her video portion consisted of a solitary speaker administering a standardized test. The audio was a taping of the same speaker. Wright was investigating whether the facial expressions of the speaker would aid listeners in comprehension. Stallings tested French language students under the same conditions. Durio and Kildow's study varied from the other two in that there was an instructional period prior to the testing of the French language students. Students met once a week in addition to their regular language classes. They were assigned to one of three treatment groups: a) listening to French language scripts; b) listening and watching the same scripts; or c) reading the scripts. None of these studies produced statistically significant findings.

Two studies, Jackson (1979) and Parry and Meredith (1984), supported the hypothesis that students who watched a videotape of a dialogue or interview would score significantly higher on a listening comprehension exam than would those students who listened only to the audio. Jackson tested college French language students. Parry and Meredith tested first, second, and third year college Spanish language students. A variable in the Parry and Meredith testing is 
that the students were tested on a multiple-choice test in English.

Live presentation was included as a variable along with audio and video in the research of Brink (1983) and Wong-Chin (1983). Brink's subjects were American students in a Fundamentals of speech class. The students were divided into three groups and were administered the same lecture via one of the three media. After the lecture, the students were given a multiple-choice test. No statistically significant differences between the listening comprehension test scores of the three groups were reported. The purpose of WongChin's study was to determine the impact of the mode of presentation on the results of a dictation test. This test was routinely given to Chinese adult ESL students as part of a placement program within the community college system. The previous method of testing had been live. Wong-Chin wanted to determine whether exams could be given by audiotape dictation or videotape without affecting the scores. WongChin's results showed no significant difference between audio and video scores. There was, however, a significant difference between live presentation and video presentation scores in favor of the live scores. The difference between live and audio, although favoring the live group, failed to reach significance.

only one study used a videotape that did not use dialogues or monologues specifically designed for a language 
testing situation. The hypothesis of Ortmeyer and Goldstein (1980) was that the audio mode, without visual representation, would be more effective than the video. Ortmeyer and Goldstein used a twelve-minute videotape, Hawail, Chinese style. This particular video was chosen because the content was culturally familiar and the language was authentic. Their results supported their hypothesis, that the audio mode alone would be more effective than the video. However, they cautioned that the results should be interpreted carefully. They felt that testing for proficiency by use of the print media can allow some interpretation of facts and allows inference; in other words, students might be able to infer answers from the multiplechoice test without actually recalling the information.

\section{SUMMARY}

Despite the current popularity of using video in the ESL classroom, there seem to be few studies available to support the superiority of video in teaching listening comprehension. In the studies mentioned above, only one used a video (Hawail, Chinese Style) that offered a wide variety of contextual clues and also visual distractions. The other videos were either focused on one speaker, or speakers engaged in a dialogue. The researchers that used dialogues do not indicate that there was any scenery or anything else that would have been a visual help or hindrance. It is 
certainly true that communication includes nonverbal communication, but research is needed to establish if the listening comprehension of $\mathrm{L} 2$ learners is assisted by the use of video, or whether video overwhelms the learner with linguistic and verbal stimuli and therefore reduces comprehension. Listening is an active process requiring the listener to work at comprehension. Listening comprehension exercises should make the listener more efficient. Research is needed to determine how video and audio can be effective components of the L2 learning process. 
CHAPTER III

METHOD

The video selected for the listening comprehension recall was a segment of the Discover television series entitled "A Wine of the Times." Students participating in the experiment were assigned to either the audio or video treatment. Comprehension of the audio or videotape was measured by the immediate recall protocol. After listening to, or viewing the tape two times, students were asked to write as many propositions (idea units) as they could within a twenty-minute period.

\section{SUBJECTS}

The study was conducted at four colleges. The number of undergraduate participants was seventy-three; graduate participants numbered three. Thirty-seven students were in the audio group and thirty-nine students were in the video group. All participating students were from Japan except for four students in the audio group and six students in the video group.

All the students who participated in the experiment had been placed in the intermediate level by their respective colleges or universities. Each school had varying criteria 
for determining placement. Usually placement was based on the combination of test scores from either the Test of English as a Eoreign Language (TOEFL) or the Michigan Test of English Language Proficiency (MTELP) and some type of oral interview. TOEFL scores were available from two schools and MTELP scores from one school. It was the policy of one of the schools not to release testing information on the students.

The TOEFL scores ranged from 350 to 537 and the Michigan scores ranged from 78 to 85 . Unfortunately, some of the TOEFL scores were composite scores (listening, grammar, and reading) while other students' scores were for listening only. This factor could not be controlled for. The listening comprehension recalls of those students who had TOEFL scores (either composite or listening only) below 420 were not included in the statistical calculations in order to narrow the range in proficiency level. Of those twelve discarded, eleven were based on TOEFL listening scores and one on a composite TOEFL score. The 420 number was selected based on a number of zero recalls received for those students who had TOEFL scores lower than 420. Twelve students' recalls were eliminated on this basis and the recall papers of two students were discarded because they fell asleep while participating in the study.

All of the students were enrolled in listening comprehension classes as part of their course of study. The 
experiment was conducted at each of the participating schools during the students' regularly scheduled listening comprehension classes. Most of the students were from Japan; with similar exposure to language learning in junior high and high school. The students were not randomly selected, but were those who had instructors who had agreed to participate in the project. Each group was tested once within a threemonth period.

\section{INSTRUMENTS AND MATERIALS}

A taped segment of the televised science program Discover was chosen for this study. The title of the segment was "A Wine of the Times," a look at the winemaking process at Mondavi Winery in Napa, California. This particular segment was chosen based on the recommendation of another ESL teacher who had found the language on the tape suitable for listening comprehension classes at the intermediate level. Among the other factors considered in the selection of this topic were student interest and prior subject knowledge. A pilot test, using the tape with other ESL students not included in this sample, indicated little background knowledge of the wine industry and its methods of research. Such prior knowledge could interfere with the recall, resulting in more elaborations. Another consideration in tape selection was length. The Discover segments are approximately fifteen minutes in length allowing the students 
to watch the segment more than once within a 50 minute class period.

The discourse consisted of narration, interview, and conversation. The average rate of presentation was 175 words per minute, the norm for speakers reading from a script (Markham, 1988).

The purpose of this listening test was to measure overall comprehension; therefore the immediate recall protocol should have greater construct validity than a multiple-choice test measuring retention of discrete items of information. The immediate recall protocol reduces the importance of memory for specific items. Recall of names or dates may be what is actually being measured on a multiplechoice listening test. The immediate recall protocol has more validity if students are able to write in their native language. The reliability of the immediate recall protocol was not specifically addressed by those who endorsed its use (see for example, James, 1986; Markham, 1988; Steffensen, Joag-dev, \& Anderson, 1979). However, the reliability of the immediate recall protocol cannot be measured in the same way as a standardized test since the test material may vary each time the test is given.

\section{PROCEDURES}

Participating students in ESL classes at four colleges were assigned to one of the two media groups, either audio or 
video. Students were given an introduction explaining the purpose of the research and describing the segment to be shown. A recall sheet given to the students listed five vocabulary words: Napa Valley; Mondavi; vineyard; barrel; and trellis. These words were selected based on a pilot study which indicated that few of the students were familiar with them. The sheet included the title of the segment as "Winemaking" so that the students would have an idea of what the text was about.

The students listened to or watched the segment twice without taking notes and then wrote down the information they were able to recall within a twenty-minute period. The amount of time allowed for the recall was determined in a pilot study. Most, if not all, students participating in the experiment seemed to have sufficient time within the twenty minutes to write down the information they remembered. One consideration for the twenty-minute recall period was the fifty-minute time frame of the listening comprehension classes at each of the colleges where the testing occurred.

\section{DATA ANALYSIS}

The independent variable is the medium used for the listening comprehension passage, either videotape or audiotape. The dependent variable is the scores of the students on the immediate recall protocol. James (1986) states, "I believe that the immediate recall protocol may 
prove to be one of the best means for determining the extent of listening comprehension of a target language text" ( $p$. 17). The type of immediate recall protocol suggested by James asks learners to write down everything they remember in their native language after listening to a text in the target language which has been read or played one time. Notetaking is not permitted. The information is scored by being compared to a transcript of the text that has been divided into idea units. A modified version of this method asking students to write down the information recalled in the $\mathrm{L} 2$ (Markham \& Latham, 1979; Markham, 1988), has been used for this study since resources were unavailable for translation of the seventy-six recalls. In this study the tape was played twice since a pilot study showed that many students had difficulty writing a recall after only one playing of the tape (audio or video).

The students wrote the information recalled in the $\mathrm{L} 2$. The scores of the students in this study were calculated in four categories on the immediate recall protocol: total idea units; macropropositions (main ideas); elaborations; and distortions (Bernhardt and James, 1987; Steffensen, Joag-dev, and Anderson, 1979). James (1986) discusses scoring of the immediate recall protocol. The protocol written by the student is "compared with a transcript of the original text and scored on the basis of recall of details, called 'idea units' in the text (p. 18)." An idea unit was defined by 
Steffensen, Joag-dev, and Anderson (1979) as a substantive, nonredundant proposition. James (1986) states that the idea units can be divided downward at the word, phrase or clause level, or upward to separate dominant ideas. For purposes of this study, each substantive nonredundant proposition was counted as one idea unit. These units were determined by the researcher and two additional raters who were native speakers of English and also ESL instructors. The total idea units for the text of the tape used in this study are listed in Appendix A. An example of one idea unit is, "Mondavi is industrial." Macropropositions were those idea units determined by the raters to be dominant ideas supported by the other idea units: for example, "Winemaking can be a matter of chance," (see Appendix B for the list of macropropositions).

The remaining statements on the recalls were scored as either elaborations or distortions. Steffensen, Joag-dev and Anderson (1979) state that there are two types of changes people make when recalling a text. Elaborations are extensions of the text, while distortions are inappropriate modifications of the text $(p, 15)$. In Appendix $C$, samples of recalls are provided. One recall lists the following elaboration, "Good wine's grapes are not good taste to eat." This information was not present in the text. An example of a distortion on another recall is, "the leaves are more important than grapes." The text talked about whether shaded 
or unshaded leaves affected the flavor of the grapes, but did not state that the leaves were more important that the grapes.

After tabulating the total idea units, macropropositions, elaborations and distortions, the scores of the audio and video groups were compared using a t-test. The researcher intended to correlate students' individual recall scores to their most recent score on the listening comprehension section of the TOEFL using linear regression. The listening comprehension section of the TOEFL is divided into three parts. Part A contains single sentences for which the student must choose another sentence that means most nearly the same as the original sentence. In Part $B$ the students listen to a short conversation between two people, then a third voice asks a question about what was said. The student must select the correct answer from those listed in the test booklet. Part $C$ contains oral readings or long conversations with several questions about each reading or conversation. The researcher was unable to test the fifth hypothesis since TOEFL listening scores were available from only one institution, while combined TOEFL scores (an average of the listening, reading, and grammar sections) were available from another institution. 
CHAP TER IV

\section{RESULTS}

The results of the measures used in the research are reported in this chapter. The college groups are identified by the letters A1, A2, B, C, and D. Two different groups were involved in the testing at institution A. The Al group consisted of those students enrolled in the regular summer session. The A2 group was composed of students who were regularly enrolled in the same university in Japan and were at institution A for a special summer session. Groups Al and $B$ were intact classes divided and assigned to either the audio or video treatment. Group $C$ was composed of two groups in separate listening comprehension classes at the same institution. At college $D$, only one group was ultimately available and this group received the video treatment. The majority of the A2 group, the last group tested, was therefore assigned to the audio group. The measures used include t-tests to compare the listening comprehension recall of the audio and video groups and t-tests to compare the AI audio and video groups with the respective groups from the other colleges. 
RESULTS OF THE IMMEDIATE RECALL PROTOCOL

One tailed t-tests were used to compare the scores of the audio and video groups on the immediate recall protocol. The t-tests analyzed the total idea units and macropropositions recalled, and the elaborations and distortions recorded by the two groups. Table I summarizes the scores of the students tested at each of the colleges.

TABLE I

TOTAL UNITS RECORDED

Groups

A1a A1v A2a A2v Ba BV Ca CV Dv

Number of Students

4

12

4

8

$\begin{array}{llll}7 & 5 & 9 & 9\end{array}$

Idea Units

$43 \quad 37$

45

$18 \quad 48$

$62 \quad 16$

$83 \quad 47$

Macropropositions

1914

3

3

17

14

$\begin{array}{lll}8 & 26 & 14\end{array}$

Elaborations

0

1

8

122

2

2

1110

Distortions

$\begin{array}{lll}7 & 10 & 29\end{array}$

59

6

6

49

$\mathrm{a}=$ Audio $\quad \mathrm{v}=$ Video

There was a significant difference favoring the video group in the total number of idea units recalled. As shown in Table II, the mean for idea units recalled by the audio group was 5.2, while the mean for the video group was 7.5 . 
TABLE II

RECALL OF TOTAL IDEA UNITS

Treatment

Audio

Video

$\star p<.05$
Mean

5.2

7.5

33
$S D$

4.3

4.5
上

$2.06^{\star}$

Table III shows a significant difference between the number of macropropositions recalled by the video group as compared to the audio group. The mean for the audio group was 1.6 with a standard deviation of 2.2 , while the mean for the video group was 2.2 with a standard deviation of 1.9 .

\section{TABLE III}

RECALL OF MACROPROPOSITIONS

Treatment

Audio

Video

$\star p<.05$ n

29

33
Mean

1.6

2.2
SD

2.2

1.9
士

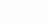
$3.59 *$

In examining the number of elaborations recorded by each group, the t-test revealed a significant difference, with the video group exceeding the audio group. Table IV shows a mean of . 4 for the audio group and 1.1 for the video group. 
TABLE IV

ELABORATIONS REPORTED

$\begin{array}{llllc}\text { Treatment } & \mathrm{n} & \text { Mean } & \text { SD } & \text { t } \\ \text { Audio } & 29 & 0.4 & 0.9 & \\ \text { Video } & 33 & 1.1 & 1.6 & -2.08 \text { * } \\ \star \mathrm{p}<.05 & & & & \end{array}$

In Table $V$, the number of distortions reported by each group are listed. The number of distortions was significantly higher for the audio group than for the video group.

TABLE V

DISTORTIONS REPORTED

$\begin{array}{lllll}\text { Treatment } & \mathrm{n} & \text { Mean } & \text { SD } & \mathrm{T} \\ \text { Audio } & 29 & 1.8 & 1.6 & \\ \text { Video } & 33 & 1.0 & 1.1 & 2.26 \text { * } \\ \star \mathrm{p}<.05 & & & & \end{array}$

In summary, the results of the t-tests show that the video group scored significantly higher than the audio group in the total number of idea units recalled, macropropositions recalled, and elaborations reported. The scores of the audio group were significantly higher in the number of distortions. 
The means and standard deviations of the total number of idea units were calculated for each college group in the audio and video treatments. This information is summarized in Tables $\mathrm{V}$ and VI. Although the testing was conducted at four colleges, there are five groups listed. Group A has been subdivided into A1 and A2. Group A1 was the regular ESL summer session class at college A. Group A2 consisted of a special summer session group of students from the same university in Japan. Students at colleges A, B, and C received both the audio and video treatments. Students at college $D$ received only the video treatment. Another class at college $D$ for which the audio treatment was selected was ultimately unavailable.

\section{TABLE VI}

MEAN AND STANDARD DEVIATION OF TOTAL IDEA UNITS AUDIO GROUPS

\section{Group}

A1

A2

B

C n

4

12

8

5
Mean

11.0

3.7

6.0

3.7

3.2

2.3 
TABLE VII

MEAN AND STANDARD DEVIATION OF TOTAL IDEA UNITS
VIDEO GROUPS

Group

n

Mean

SD

A1

4

9.3

5.4

A2

4

4.5

4.7

B

7

8.9

2.5

C

9

9.2

5.9

D

9

5.2

2.3

Since the mean for the Al audio group was much higher than the mean for any other group, $t$-tests were performed to determine if there was any significant difference between the Al group and the other groups. The tests verified that there was a significant difference between the scores of the AI audio group and the $\mathrm{A} 2$ and $\mathrm{C}$ audio groups. Table VIII lists the $t$-scores for each of the comparisons. 
TABLE VIII

COMPARISON OF A1 AUDIO GROUP

WITH OTHER AUDIO GROUPS
a) Groups
n
Mean
SD
t
A1
4
11
6.2
$2.26^{*}$
A2
12
3.7
3.1
b) A1
4
11
6.2
$1.49^{*}$
B
8
6
3.7
C) A1
4
11
6.2
$2.39 *$
C 5
3.2
2.3

$\star \mathrm{p}<.05$

T-tests were also performed to compare the A1 video group with the other groups. The means of the $\mathrm{A} 1, \mathrm{~B}$, and $\mathrm{C}$ groups were very close, as shown in Table VII.

T-tests were therefore used to analyze only the differences between the $A 1$ and $D$ groups, and the $A 1$ and $A 2$ groups. Table IX reveals that in the audio group, there were no significant differences between the A1 group and the other groups. 
TABLE IX

\section{COMPARISON OF A1 VIDEO GROUP}

WITH OTHER VIDEO GROUPS

Groups

a) $\mathrm{A} 1$

A2

b) A1

D

$\star \mathrm{p}<.05$
Mean

9.3

4.5

9.3

5.2
SD

5.4

4.7

5.4

$1.46 \star$

To summarize, no significant differences were found within the video group between Al and the other groups. However, within the audio group, significant differences were found between the $\mathrm{A} 1$ and the $\mathrm{A} 2$ and $\mathrm{C}$ groups.

Another question to be considered is whether the scores of the entire audio group and the entire video group approached a normal distribution. Histograms of the relative frequency of the scores for total idea unit recall of the audio and video groups are shown in Figures 1 and 2 respectively. Figure 1 shows a disproportionate number of low scores. A zero score does not necessarily indicate that the student wrote nothing. Only one student indicated that she couldn't remember anything. However, the recalls of some students consisted only of elaborations and distortions. This large number of low scores could be due to a variety of factors. Since the sample was not generated randomly among a large population, this particular group might have been 


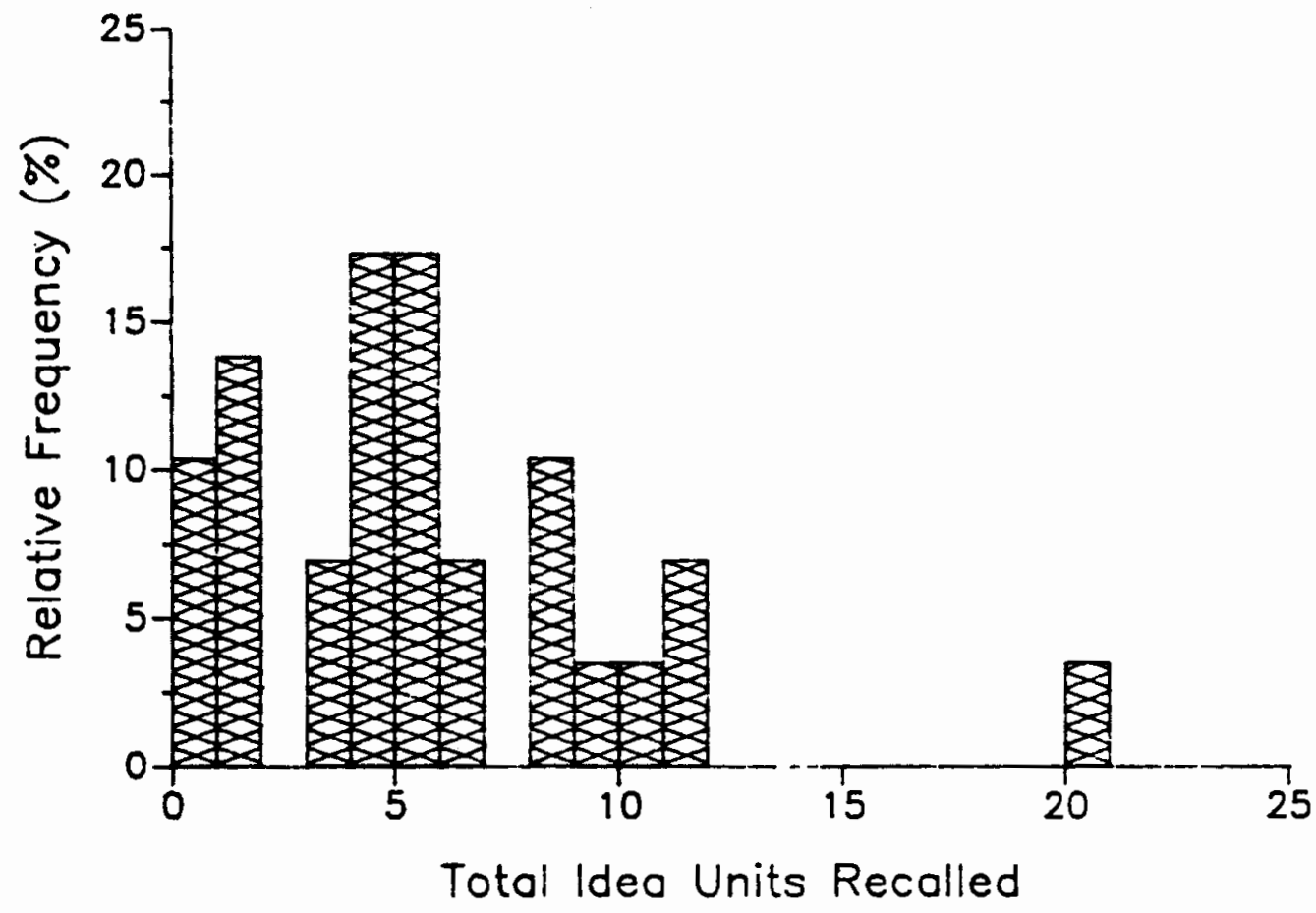

Eiqure 1. Total Idea Units Recalled - Audio

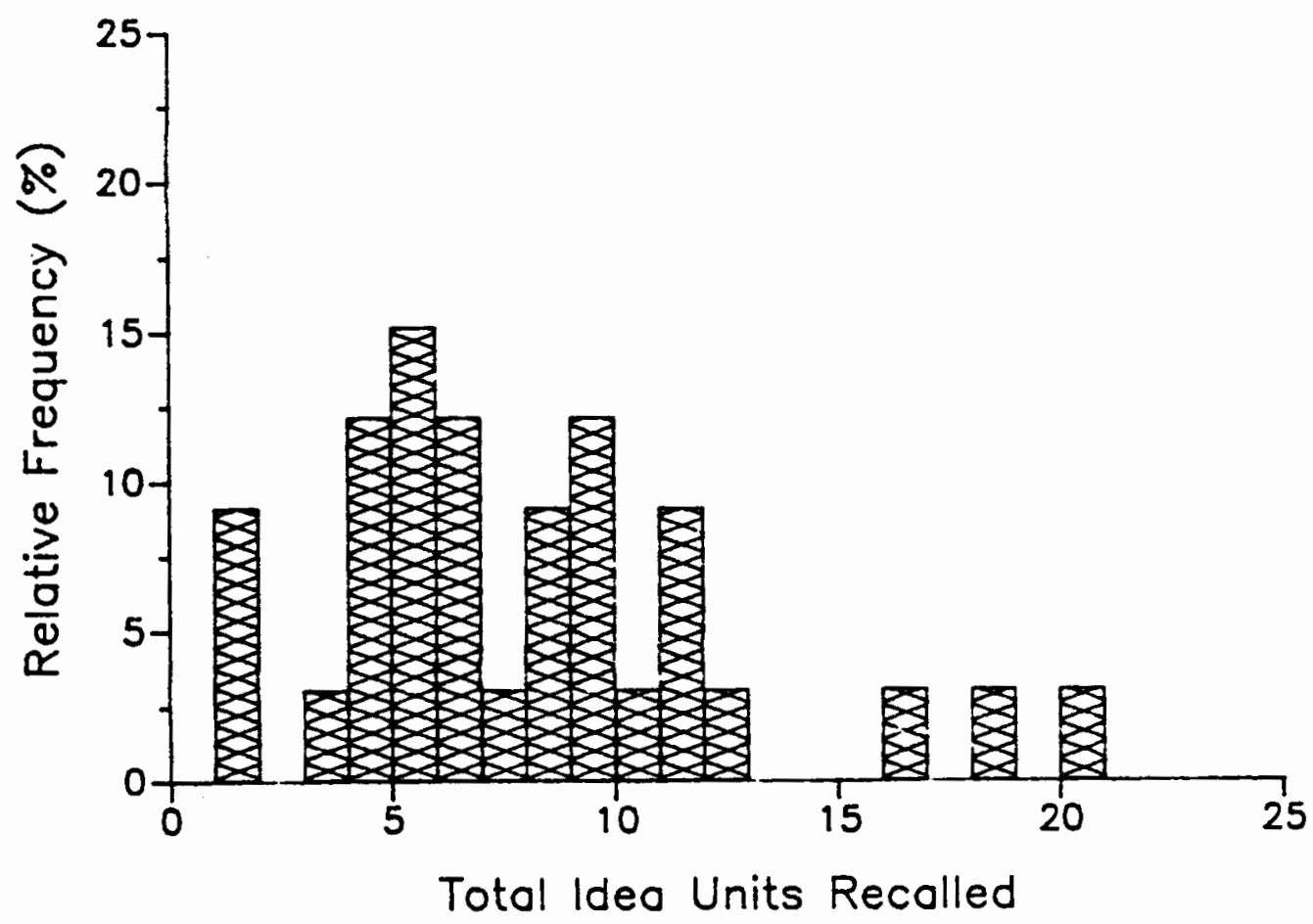

Eigure 2. Total Idea Units Recalled - Video 
disproportionately composed of students at a lower level of listening comprehension proficiency than the students in the video group. Another factor contributing to the low scores might have been the language level of the tape. If the two groups were composed of students at the same level of listening comprehension, then the low scores for the audio group would indicate that the addition of visual stimuli assisted the listeners in their comprehension of the taped segment.

The video group not only had higher recall of the number of idea units, but also recalled more macropropositions. The frequency scores for the macropropositions recalled are shown in Figures 3 and 4 . The video group (Figure 4) demonstrated a much wider range of scores, with a gradual slope from those at zero macropropositions to those at eight. On the other hand, in the audio group, 458 of the students reported no macropropositions and the percentage of students recalling one macroproposition drops sharply to 178. The video group also reported fewer distortions. Possibly the addition of the visual element cleared up misinterpretations based on the linguistic element alone. Just as with the scores for total idea units recalled and macropropositions recalled, the scores for the distortions reported appear more normally distributed on the histograms (see Figures 5 and 6). Finally, the video group reported more elaborations of information. Figures 7 and 8 compare the distributions of 


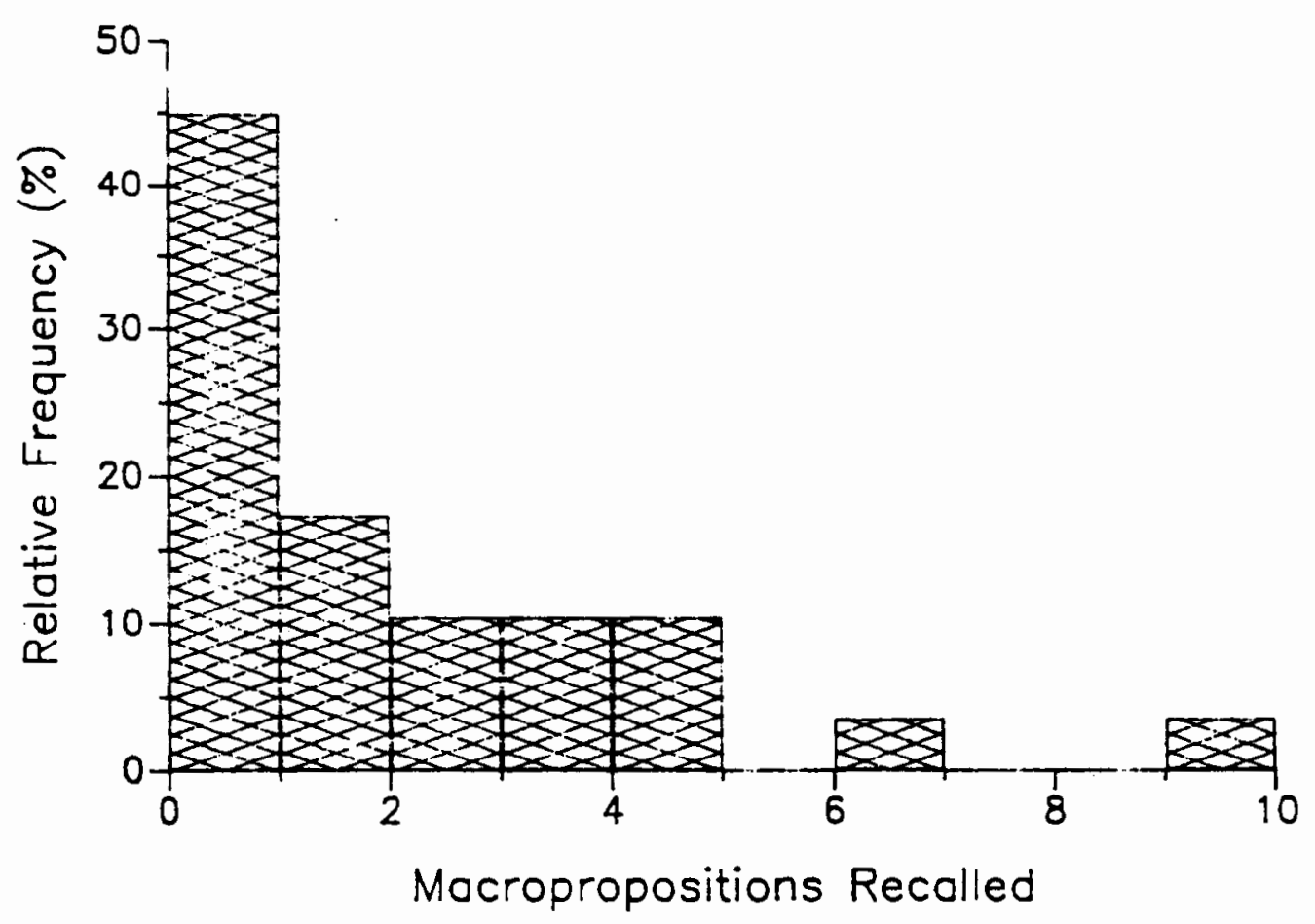

Eigure 3. Macropropositions Recalled - Audio

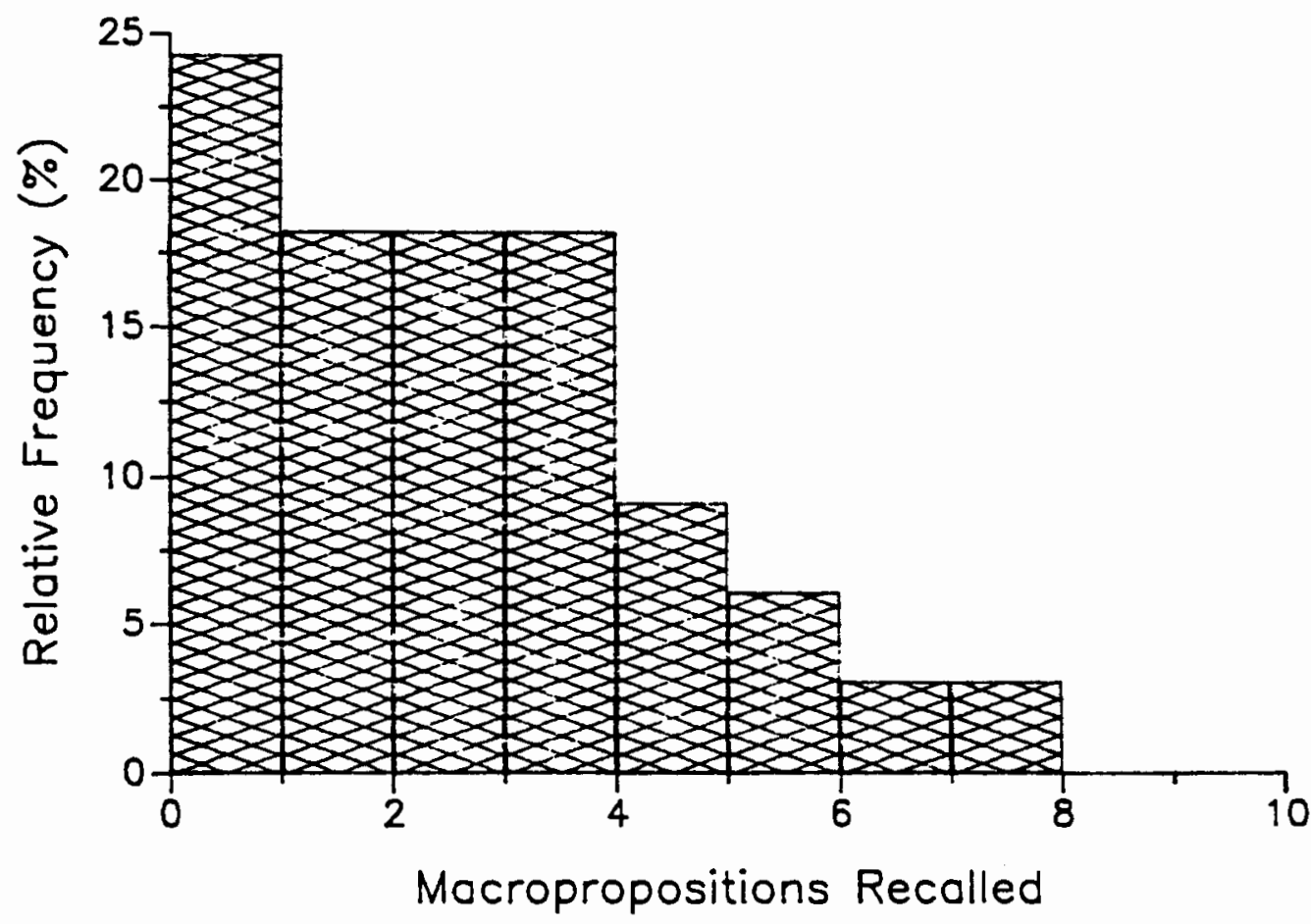

Eigure 4. Macropropositions Recalled - Video 


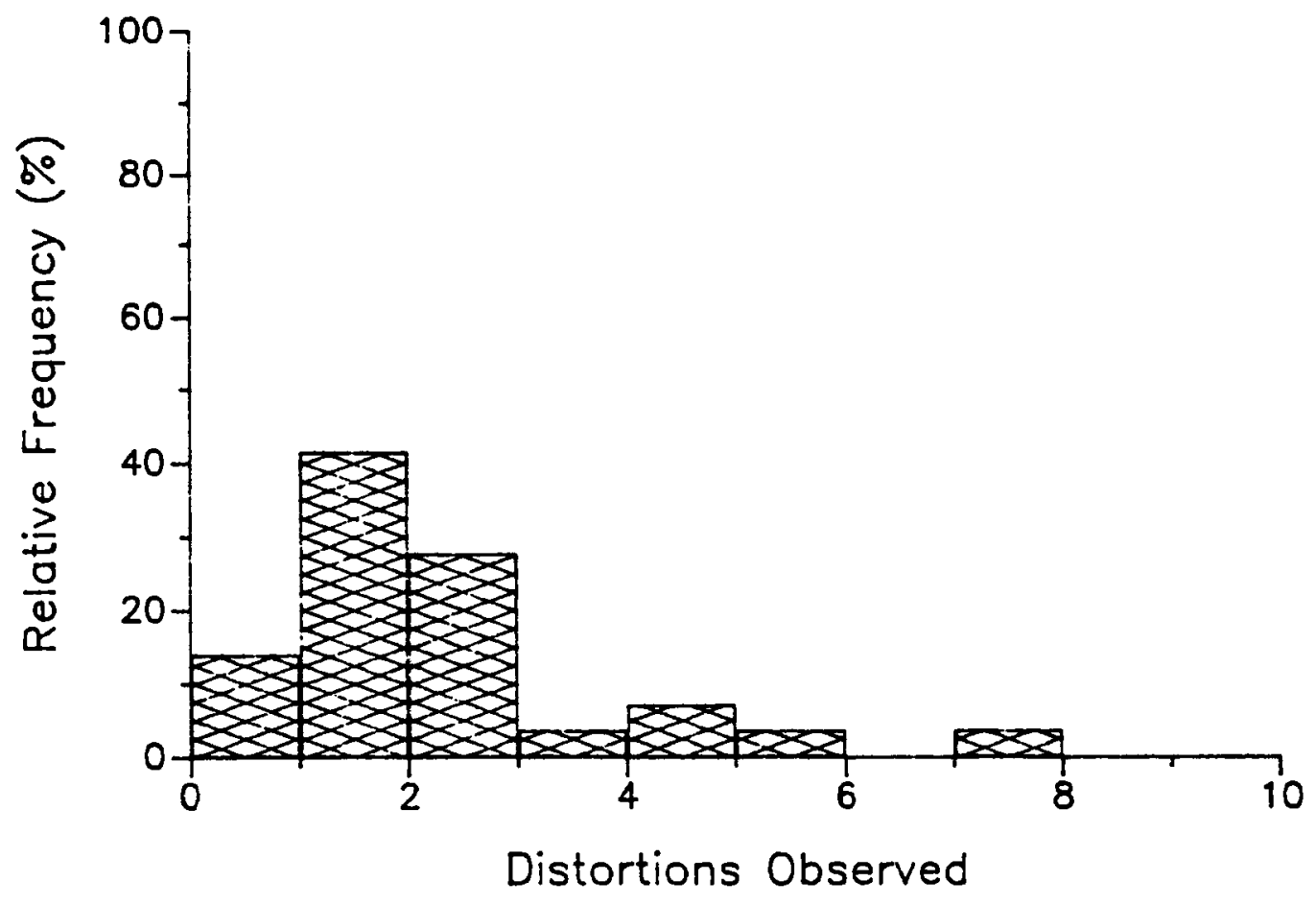

Eigure 5. Distortions Observed - Audio

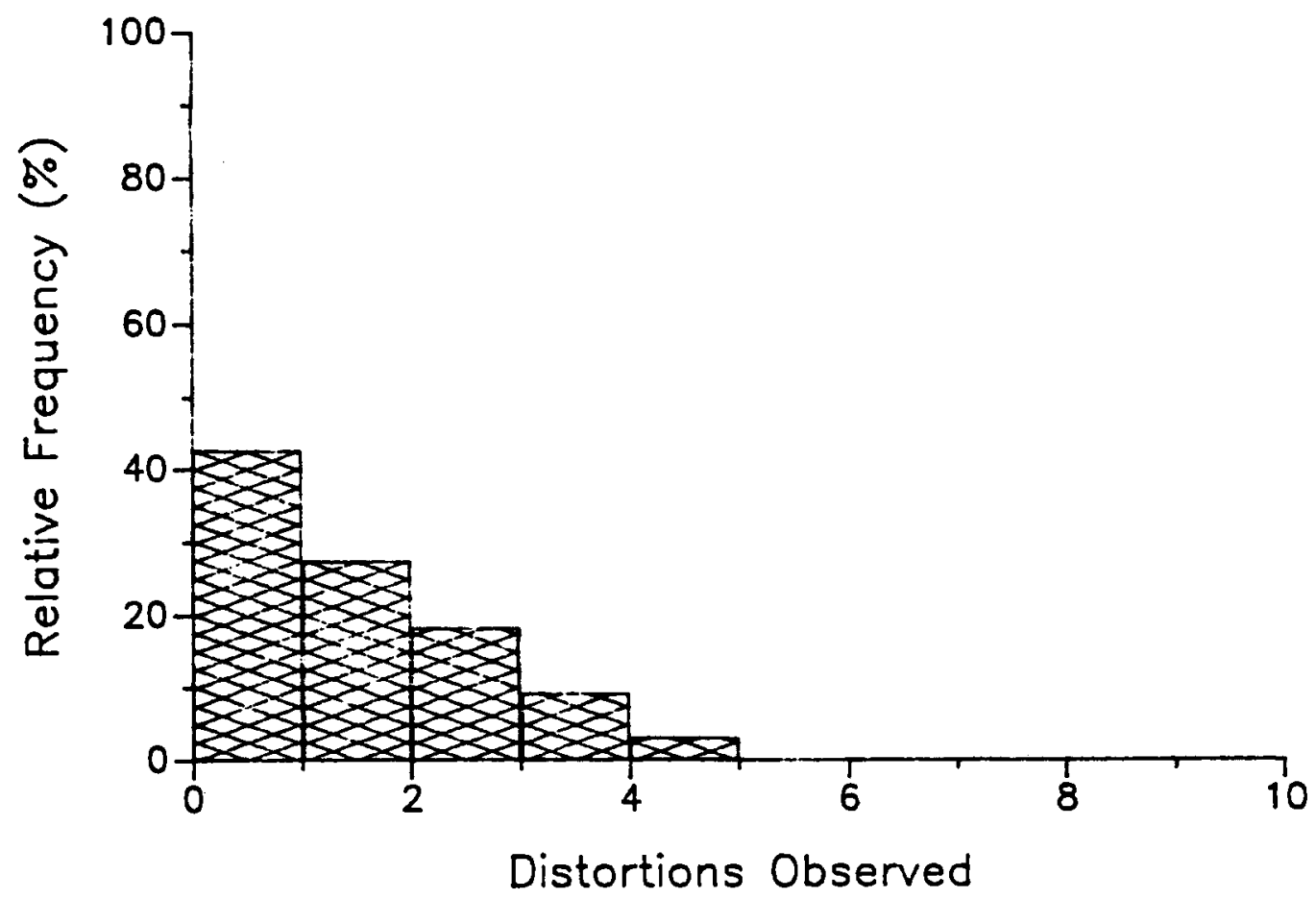

Eigure 6. Distortions Observed - Video 


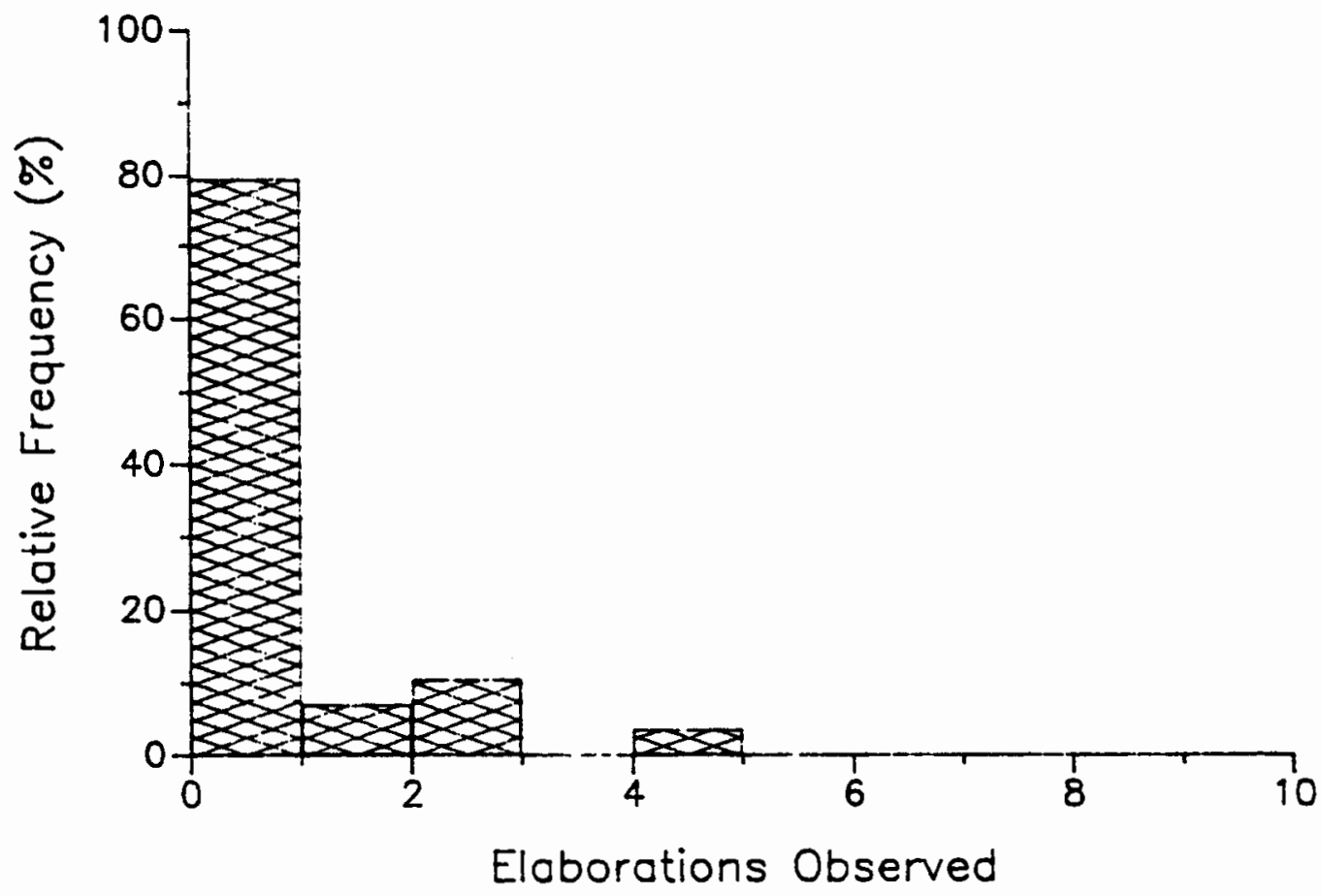

Eigure 7. Elaborations Observed - Audio

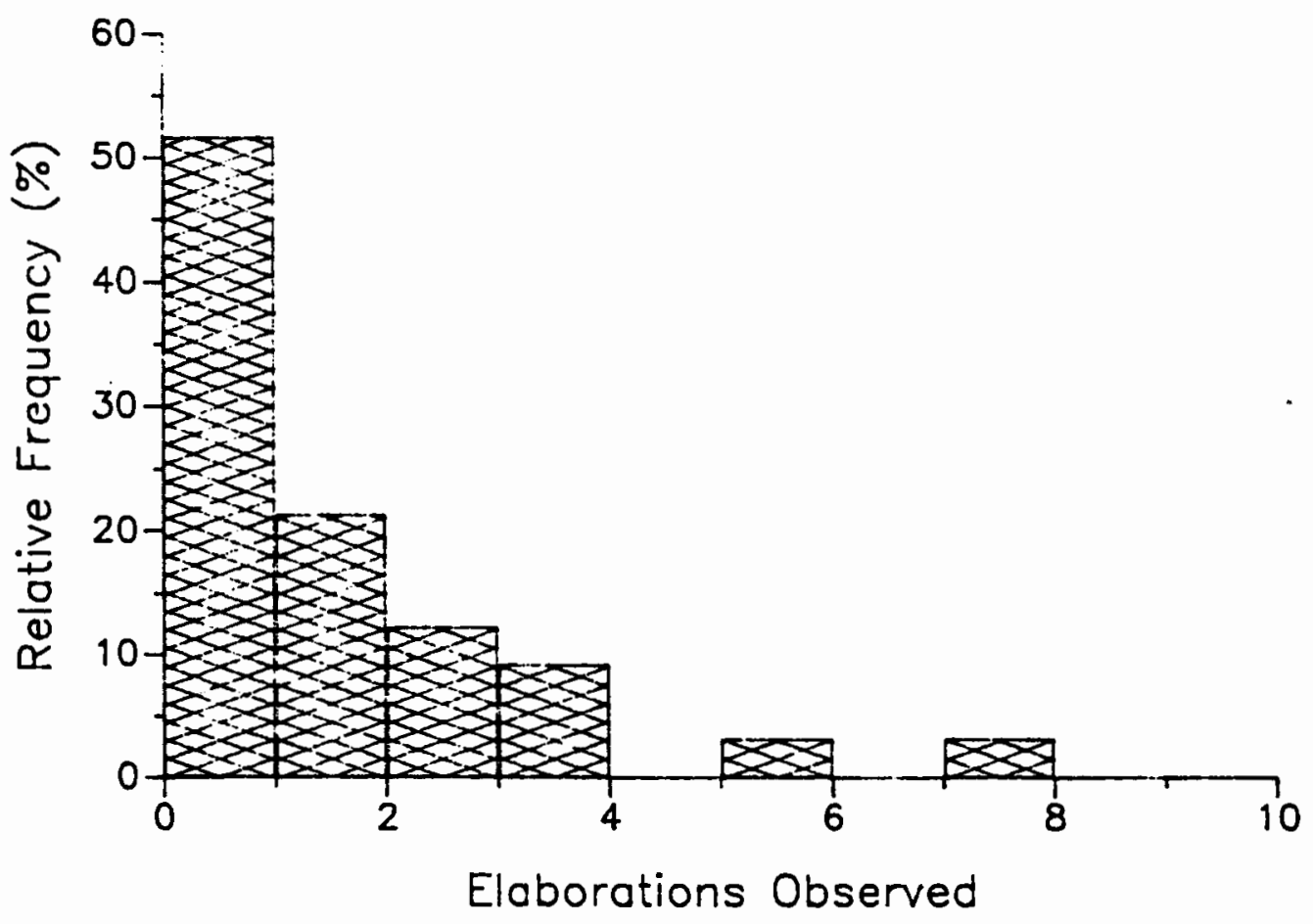

Eigure 8. Elaborations Observed - Video 
elaborations reported. Almost $80 \%$ of the audio group (Figure 7) did not elaborate at all. The figure for the video group was almost 508 (Figure 8). A clearer comprehension of the content of the video may have triggered recall of related information learned previously.

The implications of these findings will be discussed in relation to the hypotheses presented. Support for the hypotheses could help clarify the value of audio in listening comprehension classes. Lack of support for the hypotheses creates an opportunity to investigate those factors responsible. These investigations can also provide useful insights into the listening comprehension process. 
CHAPTER V

INTERPRETATION OF RESULTS

In general, those students receiving the video treatment outperformed the students receiving the audio treatment. The types of differences in the scores of the groups will be examined as well as the differences among the student populations tested.

INTERPRETATION OF THE IMMEDIATE RECALL PROTOCOL RESULTS

The results of the immediate recall protocol did not support the hypothesis that the students listening to an audiotape would score higher than students watching a videotape of the same material. In fact, the video group scored significantly higher than the audio group. Previous studies comparing audio and video had yielded a variety of results, some favoring video, one favoring audio, and some showing no significant difference (see for example: Jackson, 1979; Parry \& Meredith, 1984; Wright, 1971; Stallings, 1971; Durio \& Kildow, 1979; Brink, 1983; Wong-Chin, 1983; and Ortmeyer \& Goldstein, 1980). However, the studies were not directly comparable because of the variety of audio and video materials used. Many of the video tapes were made by the researcher for the particular project. One study used 
twenty-seven dialogs of varying levels of difficulty (Parry \& Meredith, 1984). The dialogs ranged in length from twenty seconds to one minute. The video used by ortmeyer and Goldstein was twelve minutes long. These studies did not give information on rate of presentation (words per minute), a factor which could strongly affect comprehension.

The hypothesis that the audio group would score higher on a listening comprehension recall than the video group was based on classroom observation. In asking students to listen for particular items of information while watching a videotape, it was observed that many students would close their eyes to listen to the audio portion, shutting out any visual distractions. A study by Drew and Cadwell (1985) conducted on broadcasting students concluded that viewers of television news tended to focus on audio and did not react to visual discontinuity. "Subjects apparently were unable to attend to both channels simultaneously so they concentrated on the one that traditionally contains the 'factual' information (audio)" (p. 831).

In this study, the results do not support the hypothesis that the audio group would recall more than the video group. Since the reverse was true, the possible causes for this outcome need to be examined.

One of the major variables among the studies conducted by researchers comparing audio and video has been the taped material used. As mentioned earlier, many of the studies 
used tapes made specifically for the particular research project. In the one study in which students receiving the audio treatment scored higher than the video treatment, a commercial tape was used, Hawail, Chinese style, The intent of this study was to find a similar commercial tape providing not only nonverbal cues to the audio portion, but also providing nonverbal distractions. This tape would have a script related to but not redundant with the video. The issue of tape selection was never optimally resolved. It was beyond the resources of this project to create a movie-type video with a script lasting seven to fifteen minutes. The researcher was unable to obtain any assistance in tape selection from local broadcasting companies, although permission was granted to tape and use programs from PBS broadcasting. After one month and countless hours of video viewing, the researcher selected a tape based on the recommendations of another ESL teacher. The testing subsequently revealed that the particular tape selected was too difficult for the level being tested (based on a number of zero recall scores). The tape was an educational segment from the PBS Discover series on research methods in the wine industry. Much of the video portion reinforced the audio, possibly contributing to the much higher recall scores for the video group. Had the visual segment been composed of a combination stimuli both related and unrelated to the audio, the results of this study might have been different. 
In summary, of the four hypotheses related to recall of information, only one was supported by the research in this study. The audio group reported fewer elaborations of information. Had the other hypotheses been supported, if the audio group had recalled more total idea units and more macropropositions, and reported fewer distortions, then perhaps the fact of their also having fewer elaborations might be meaningful. However, with the lack of support for the other three hypotheses, the reporting of fewer elaborations seems to be based on a poorer understanding of the tape, rather than a better understanding of it. In this study, the students receiving the video treatment received significantly higher scores than students receiving the audio treatment. However, in any attempt to generalize the advantages of video one must consider the material being used. Messages can be reinforced by visual elements, but distractions can also be introduced. Another difficulty in attempting to generalize the findings of this study involves the score distributions of the groups. In each analysis, the distribution of scores was more normal for the video group than the audio group. More research would be needed to determine whether these distributions were due to the media used or to differences in the subjects composing the two groups. 
INTERPRETATION OF THE COMPARISON OF GROUPS

This research was quasi-experimental due to the inability to randomize the groups. However, the differences in the sample populations certainly has an impact on the study and cannot be ignored. By calculating the means of the total idea units for the various participatory groups, it becomes apparent that the mean for the A1 group was much higher than for the other groups. As see in Tables VIII and IX, there was a significant difference between the scores of the $A 1$ audio group and the $A 2$ and $C$ audio groups. This difference did not exist within the video group.

The students who participated in the study in the A1 group had been enrolled in a listening comprehension class of the researcher and therefore may have been more familiar with documentary-type videos such as the one that was used in the study. Since five groups participated in the study, there was probably a wide range of student language learning methods. There was no way to control for this variation.

Environmental factors may also have influenced the study and were not controlled for. Due to program limitations and time constraints, students were tested in their regular listening comprehension classes at their respective colleges. The physical conditions varied at each of the colleges. At one of the colleges, all the students were in a language laboratory and had individual headsets. The students receiving the video treatment had individual monitors. In 
another class situation, the class was divided with the video students facing forward watching the monitor and the audio students facing the back of the room. It is possible that some students felt disappointed at having to sit backwards and face the wall, while other students watched a video. In another treatment, the classroom had a large area of window space and students were observed staring out the window rather than watching the monitor. During one testing situation, there was a temporary problem with the audio portion (however this group was part of the video group and their scores were not significantly different from any of the other video groups).

Not only the variance in physical conditions could have affected the results, but also the student attitude toward the research. Since the $A 1$ students knew the researcher and were concurrently enrolled in the researcher's listening comprehension class, they could have been highly motivated to pay attention. At some of the other schools, students fell asleep. Some of these students were observed by the researcher, others wrote on their recall sheets that they had fallen asleep and therefore could not recall any information. These recalls were not included in the survey count. It is possible that some of the other recalls with a zero score were also due to the student having fallen asleep.

The students were not volunteers. Their teachers had agreed to cooperate with the researcher. Since the students 
were advised that the recall was not an item to be graded, some of the students may have regarded the testing day as a "free day," free of any learning responsibilities. Rather than creating a Hawthorne effect, with students eager to participate, the situation may have been the reverse.

The findings of this study do not support four of the five hypotheses presented in Chapter one. The video group scored higher on recall of total idea units and macropropositions. The video group also recorded fewer distortions. The only hypothesis supported was that the audio group would have fewer elaborations on the immediate recall protocol. Because of the difference in the types of TOEFL scores provided by the schools, the fifth hypothesis could not be tested. 


\section{CHAPTER VI}

\section{CONCLUSIONS AND RECOMMENDATIONS}

This study was conducted because of the increasing use of video without clear definition as to its role, and the concurrent decline in the use of audiotapes. The hypotheses were based on the researcher's classroom observations. The study was conducted with 73 students at four colleges who were assigned to either the video or audio treatment. The students either listened to or watched a video and then wrote an immediate recall protocol to measure listening comprehension. Five hypotheses were tested based on the scores on the listening comprehension recalls.

The first hypothesis suggested that the audio group would recall more idea units than the video group. This hypothesis was not supported; in fact, the scores of the video group were significantly higher than those of the audio group. The second hypothesis stated that the audio group would report fewer elaborations than the video group. This hypothesis was supported by the scores received. However, based on the collective data, it appears likely that fewer elaborations were reported by the audio group because they understood less of the text and consequently wrote shorter recalls, rather than because they had a better understanding 
of the text. The third hypothesis proposed that the audio group would report fewer distortions than the video group. This hypothesis was not supported. The video group scored significantly higher than the audio group. The fourth hypothesis also was not supported. This hypothesis stated that the audio group would remember more macropositions than the video group. Again, the scores of the video group were significantly higher than the scores of the audio group. The final hypothesis proposed that the scores of the audio group would correlate with their TOEEL listening scores. This hypothesis was not tested since TOEFL listening scores were unavailable for a majority of the students.

Listening comprehension is an important component of the language learning process; however, according to Richards (1983), there has been little research on second language listening comprehension. With the low cost and availability of videotapes, this medium has been increasingly used in the ESL classrooms. Audiotapes, which were an integral part of the audiolingual teaching method, are criticized as lacking visual cues. A need has existed for research to investigate the roles of audio and video in the language learning process. Several researchers have conducted studies to determine whether language learners comprehend more text via the audio or audio-visual modes. None of the studies mentioned in Chapter Two attempted to replicate one another, 
and only one of the studies was performed with ESL students. There is still much work to be done in this area.

Until recently, very often listening comprehension teaching was not much more than listening comprehension testing. Students were graded on their listening comprehension by how well they were able to understand and recall certain facts. Most listening comprehension materials provided necessary vocabulary, but little in the way of skills for listening.

With the advent of the communicative approach, there has been an increased emphasis on meaning conveyed not just by the words themselves, but also by the combination of the knowledge of the language system, knowledge of the situation, and background knowledge. Anderson and Lynch (1988) refer to these three factors as systemic (linguistic) knowledge, context, and schematic knowledge. Contextual knowledge is aided by visual cues provided in the video medium. Consequently, the use of the video medium has recently proliferated in language learning classrooms.

Why should there be any concern over the use of video? Some studies have shown that in a conflict between the two media (audio and video) it is the linguistic mode that is ignored. If the purpose of ESL is language teaching, then situations should not be created in the classroom where language is ignored. Some listening comprehension exercises, in an attempt to create an "active viewing situation" ask the 
learner to recall such details as articles of clothing. While a uniform may help a learner create a schema for the situation, ordinarily recall of the color or type of clothing bears little relation to the speech stream.

\section{CONCLUSIONS FROM STUDY}

The results of this study lend support to the use of video as a means of increasing listening comprehension under certain conditions. The video group's scores were significantly higher than the audio group in recall of both total idea units and macropropositions, and video should certainly be considered a useful tool in the classroom. Although the audio group did not perform as well as the video group, it cannot be concluded that video is always the best medium for teaching listening comprehension skills. This study underscores the need for further research with the audio and video media under different types of conditions. One variable which could be tested would be a comparison of different types of taped material (such as movies, documentaries, or lectures) with the same audio and video groups in order to determine if the video group would consistently score higher on a variety of material. This study supported video as an effective means of increasing listening comprehension with the use of a taped documentary for intermediate level students. Another variable could involve a different method of measuring comprehension. Part 
of the audio group could do an immediate recall protocol while the other part could do a multiple-choice test. The same division could be made within the video group. Research is also needed to establish the reliability of the immediate recall protocol. A third variable might involve testing each subject twice, once after an exposure to an audiotape and once after an exposure to a videotape. If all subjects score either consistently high on both the audio and video recalls, or consistently low on both recalls, there would be evidence to support the premise that rather than the media affecting the scores, an intervening variable such an intelligence or prior instruction had affected the scores. Numerous variables could be tested and possibly help clarify the most effective roles for audio and video in second language acquisition.

\section{IMPLICATIONS FOR TEACHING}

These results provide more questions than answers. In selecting audio or video materials for classroom use, the teacher must analyze what the object of the lesson is and what skills are being taught. Consideration must be given to the students' proficiency levels, their goals for learning English, and their interest in the material being presented. Video can help provide an overall understanding of the tape if the visual clues are redundant with the linguistic stream. For some lessons, the use of audio may be superior, as in 
understanding such speech patterns as rhythm and stress, use of pauses, reduced forms and cohesive devices. This study emphasizes the need for continuing research in the area of listening comprehension and accentuates the importance of selecting media based on curriculum goals.

\section{SUMMARY}

There are many limitations to a study such as this one. First there was the inability to randomize the students. Students were chosen based on their level (intermediate) and availability. Another factor that could not be controlled was prior education. Some students may have worked more with audiotapes and therefore felt more comfortable listening to them than others. Other students may have watched more television or movies and therefore have been more comfortable with the video format. There is always the possibility that whatever video was chosen, some students may have had background knowledge contributing to their understanding of the passage regardless of the media.

Lack of support for the hypotheses in this study does not indicate that video is always the superior medium for listening comprehension. Further research is needed to determine the roles of audio and video in teaching listening comprehension to intermediate level ESL students. The current popularity of video in classroom use should be supported by research that analyzes under what conditions 
video can most effectively contributes to the language learning process. 
REEERENCES

Anderson, A. \& Lynch, T. (1988). Listening. Oxford: Oxford University Press.

Asher, J. (1981). Comprehension training: The evidence from the laboratory and classroom studies. In $H$. Winitz (Ed.), The comprehension approach to foreign language instruction (pp. 187-222). Rowley, MA: Newbury House.

Bernhardt, E.B., \& James, C. J. (1987). The teaching and testing of comprehension in foreign language learning. In D. Birckbichler (Ed.), Proficiency, policy, and professionalism in foreign language education. Selected papers from the 1987 Central states Conference. (Alexandria, VA: ERIC Document Reproduction Service, No. ED 285420,18 p.)

Brink, R.I. (1983). The effect of medium of instruction on the listening comprehension and retention of community college speech students. Dissertation Abstracts International, 44/11A, 3261 .

Byrnes, A. (1982). Enhancing second language acquisition by a focus on listening comprehension: The potential of the cassette. Eoreign Language Annals, 15, 37-46.

Byrnes, H. (1984). The role of listening comprehension: A theoretical base. Eoreign Language Annals, 17. 317329 .

Call, M.E. (1985). Auditory short-term memory, listening comprehension, and the input hypothesis. TESOL Quarterly, 19, 765-781.

Carr, T. \& Duncan, J. (1987). The VCR revolution: Feature films for language and cultural proficiency. In $D$. Birckbichler (Ed.), Proficiency, policy, and professionalism in foreign language education. selected papers from the 1987 Central states Conference. (Alexandria, VA: ERIC Document Reproduction Service, No. ED 285422,15 p.) 
Cosgrove, J.M. \& Patterson, C.J. (1977). Plans and the development of listener skills. Developmental Rsychology, 13, 557-564.

Dahl, R. (1984). High technology, language learning, and nonverbal cultural literacy. Unterrichtspraxis, 17, 6675 .

Danahy, M. (1985). TV or not TV? In J. Gillespie (Ed.), Videe and second Language Learning. Alexandria, VA: ERIC Document Reproduction Service, No. ED 278246,8 p.

Drew, D. G. \& Cadwell, R. (1985). Some effects of video editing on perceptions of television news. Journalism ouarterly, 62, 828-31.

Durio, H. \& Kildow, C. (1979). Video, audio and reading instructional presentation of six French language scripts: An evaluation of a listening comprehension study. (Alexandria, VA: ERIC Document Reproduction Service, No. ED 188444,55 p.)

Gary, J. O. (1979). Why speak if you don't need to? The case for a listening approach to beginning foreign language learning. CATESOL Occasional Papers. No. 5. (Alexandria, VA: ERIC Document Reproduction Service, No. ED 187148,16 p.)

Hare, V. \& Devine, D. (1983). Topical knowledge and topical interest as predictors of listening comprehension. Journal of Educational Research, 76/3, 157-60.

Hartman, R. R. (1961). Single and multiple channel communications: A review of research and a proposed model. Audio-Visual Communication Review, 16, 245-267.

Ironsmith, M. \& Whitehurst, G. (1978). How children learn to listen: the effects of modelling feedback styles on children's performance in referential communication. Developmental Psychology, 14, 546-554.

Jackson, O. I. (1979). The effects of video vs. audiotaped interviews on listening comprehension in third-quarter, beginning college French. Dissertation Abstracts International, 40/07A, 3841 . 
James, C. H. (1986). Erom principles to protocols: The contributions of John B. Carroll and Robert Lado to the testing of listening comprehension. Paper presented at the Language Testing Symposium, Quiryat Anavim, Israel. (Alexandria, VA: ERIC Document Reproduction Service, No. ED 278107,54 p.)

James, C. J. (1984). Are you listening? The practical components of listening comprehension. Foreign Language Annals, 17, 129-133.

Krashen, S. (1981). Second Language Acquisition and Second Language Learning. Oxford: Pergamon.

Lonergan, J. (1984). Video in Language Teaching. Cambridge: Cambridge University Press.

MacWilliam, I. (1986). Video and language comprehension. ELT Journal, 40, 131-35.

Markham, P. L. (1988). Gender and the perceived expertness of the speaker as factors in ESL listening recall. TESOL euarterly, 22, 397-406.

Markham, P. L. \& Latham, M. (1987). The influence of religion-specific background knowledge on the Iistening comprehension of adult second language students. Language Learning, 37, 157-170.

Morley, J. (1980). Active participation/purposeful listening in the language laboratory: Aspects of theory and practice. SPEAO Journal, 4, 25-54.

Mueller, G. A. (1980). Visual contextual cues and listening comprehension: An experiment. Modern Language Journal, $64,335-340$.

Nord, J. R. (1981) Three steps leading to listening fluency: A beginning. In $\mathrm{H}$. Winitz (Ed.), The Comprehension Approach to Eoreign Language Instruction (pp. 69-100).

Ortmeyer, C. R. \& Goldstein, B. L. (1980). Comparing modes ef instruction used in learning to listen to and understand English as a second language. Alexandria, VA: ERIC Document Reproduction Service, No. ED 202 240, 15 P.

Parry, T. \& Meredith, R. A. (1984). Videotape vs. audiotape for listening comprehension tests: an experiment. OMLTA 
Journal, 47-53. (Alexandria, VA: ERIC Document Reproduction Service, No. ED 254 107, 8 p.)

Porter, D. \& Roberts. Authentic Listening Activities. In M.

H. Long \& J. C. Richards (Eds.), Methodology in TESOL: A Book of Readings. (pp. 177-187). Rowley, MA: Newbury House.

Postovosky, V. The priority of aural comprehension in the language acquisition process. In H. Winitz (Ed.), The Comprehension Approach to Foreign Language Instruction, (pp. 170-186). Rowley, MA: Newbury House.

Richards, J. C. (1983). Listening comprehension: Approach, design, procedure. TESOL Ouarterly, 17, 219-240.

Rivers, W. (1983). Speaking in many tongues. Cambridge: Cambridge University Press.

Samuels, G J. (1984). Factors influencing listening: inside and outside the head. Theory into Practice, 23, 183-189.

Stallings, W. M. (1972). A comparison of television and audio presentation of the MLA French listening exam. Journal of Educational Research, 65, 472-474.

Steffensen, M.S., Joag-dev, C. \& Anderson, R. C. (1979). A cross-cultural perspective on reading comprehension. Reading Research Ouarterly, 15, 10-29.

Svensson, S. E. \& Bogarskola, M. (1985). Video, authenticity, and language for special purposes. Eoreign Language Annals, 18, 149-52.

Ur, P. (1984). Teaching Listening Comprehension. Cambridge: Cambridge University Press.

Widdowson, H. G. (1978). Teaching language as communication. Oxford: Oxford University Press.

Winitz, H. (1981). A reconsideration of comprehension and production in language training. In H. Winitz (Ed.), The Comprehension Approach to Foreign Language Instruction (pp. 101-140) Rowley, MA: Newbury House.

Wong-Chin, E. (1983). The Effect of Mode of Presentation on English Aural Comprehension among Chinese Adult Englishas-a-second Language Students. Unpublished doctoral dissertation, University of San Francisco, San Francisco. 
Wright, S. M. (1971). Effect of speaker visibility on the listening comprehension test scores of intermediate level students of ESL. Dissertation Abstracts International, $32 / 04 \mathrm{~A}, 2080$. 
APPENDIX A

IDEA UNITS 
TOTAL IDEA UNITS

1. Chateau Margeaux '23 is a great wine.

2. Every winemaker would like to make the best possible wine.

3. Winemaking can be a matter of chance.

4. Wine is a product of nature.

5. It is a product of the soil the grapes grow in.

6. It is a product of the climate.

7. It is a product of the weather in a particular year.

8. In California there is a winemaker who is discovering there may be more ways to make a great wine than most of his colleagues think.

9. Napa Valley, California, is America's Finest wine region.

10. It has lush vineyards.

11. It produces wine that nearly equals the very best from France.

12. Robert Mondavi is one of the most successful wineries here.

13. A cabernet wine is in the making that may finally surpass the Erench.

14. Mondavi is typical of American wineries.

15. It is big.

16. It is industrial. 
17. Here winemakers are influencing the taste of their wine in unprecedented ways.

18. Tim Mondavi is the chief winemaker.

19. Wine is an issue of balance.

20. Wine is an issue of flavor.

21. Wine is an issue of life.

22. Wine is an issue of character.

23. Wine is an issue of texture.

24. All of those elements come together.

25. The essence is when nothing is obvious and everything is glorious.

26. It's a symphony.

27. It's where no instrument is too loud.

28. At Mondavi, they're taking a systematic approach to achieving that symphony.

29. It begins with regular wine tastings.

30. Mondavi cabernet is compared to the finest from France. 31. The goal is to see how Mondavi's best cabernet might get even better.

32. Each wine here has a distinct character.

33. When the winemakers agree on what they like best, they try to figure out what makes a cabernet taste that way.

34. The approach is very American.

35. It's interesting when we have gone to France and we ask people "why is this so wonderful?"

36. They say it is zee sun. 
37. They say it is zee soil.

38. What did you do?

39. I did nothing.

40. In France there has always been a strong belief that the plot of land is what determine how grapes and wine taste.

41. A winemaker can't do much in a vineyard other than to choose the right land.

42. The best wines seem to come from places where grapevines are small.

43. Here they barely reach a person's waist.

44. Is the size of the vine the key?

45. Tim Mondavi and all Napa winemakers may have a handicap. 46. Here, vines grow bigger and bushier than in France.

47. The weather is warmer.

48. The soils are richer.

49. The grape growers in the past have selected bigger vines.

50. Tim has noticed his biggest vines produce cabernet grapes with a less pleasant balance of flavors.

51. Fine cabernet can be so fragrant.

52. Eine cabernet can be so warm.

53. There's a character that will be there.

54. A blackberry taste can be there.

55. There are flowers.

56. There are deep, rich, flowers.

57. They're fruity. 
58. As opposed to cooked green beans.

59. As opposed to asparagus.

60. That's not what we're looking for.

61. The vegetable flavor isn't noticeable in most of Tim's vineyards.

62. He wants to avoid even the slightest trace of it.

63. The size of the vine might not be what really counts.

64. Tim is concerned about the effect of the shade on the vineyards.

65. The cause of the vegetable taste may be the way the grapes get shaded on big bushy vines.

66. The leaves of a grapevine act like a filter.

67. They allow green and blue light to pass through.

68. They block most of the red light.

69. In a research vineyard operated by the University of California, scientists are measuring just how much red light the leaves are filtering out.

70. They are first taking readings under full sunlight.

71. They took a reading here of fifteen hundred microeinsteins.

72. The theory is that grapes only manufacture all their potential fruit flavor when there is enough red light compared to other colors.

73. At Mondavi, bushy vines filter the light.

74. There's an experiment to correct the light balance.

75. They're tucking vine shoots up under trellis wires. 
76. They want the vines to grow straight up like a tree.

77. They don't want the vines to be bushy.

78. Leaves on the vertical trellis won't filter the light falling on the grapes.

79. If red light is crucial the grapes will get enough.

80. Tim Mondavi tried a vertical trellis last year in his bushiest vineyard.

81. He got a dramatic reduction in vegetable flavor.

82. He's trying for a subtle improvement.

83. He's trying for improvement in his best vineyards where there is no obvious vegetable flavor to begin with.

84. To have a basis of comparison, half the vineyard has been left with its old style standard trellis.

85. They are going to be making different wines from each of these trellising systems.

86. They hope to find that they prefer the wine from the vertical trellising system because of the fruit, because of the fragrance.

87. The balance of the wine itself will be more favorable than what they have seen in the past.

88. Are unshaded grapes the secret to better flavor?

89. Maybe they are not.

90. A scientist has a different idea.

91. She has an experiment here too.

92. In this experiment they are trying to make the fruit taste worse. 
93. For obvious reasons, Janice Morrison's experiment is limited to just a couple of rows.

94. Janice believes the major cause of vegetable flavor is shaded leaves.

95. She believes the cause of vegetable flavor is not shaded grapes.

96. She is training extra vines.

97. She is training the vines to put more shade on leaves.

98. She is leaving the grapes exposed.

99. The idea is to show the vegetable flavor develops even though the grapes are getting plenty of red light. 100. They are putting the vine at an angle. 101. They want to get the maximum shade on the foliage. 102. They don't want to get the fruit in the shade. 103. Why might shaded leaves cause vegetable flavor? 104. It's possible that shaded leaves are producing some compound.

105. The compound moves into the grapes and causes this vegetative character.

106. To check further on the vines, Janice is shading grapes for comparison.

107. The ultimate test of these experiments will be the wine. 108. Laboratory measurements might also detect differences. 109. Grape samples are collected throughout the growing season. 
110. Their juice is analyzed to follow the development of sugars and acids.

111. Grape skins which contain most of the flavor and color compounds are liquified.

112. They are analyzed.

113. At Mondavi, laboratory measurements also help determine when the grapes are ripe and ready to harvest.

114. As cabernet grapes arrive at the winery by the ton, the winemaking process begins.

115. There is a crusher.

116. The crusher has a spiral screw which gently pulls the grapes and stems apart.

117. The stems pile up outside.

118. The grapes and juice get pumped inside.

119. The stainless steel tanks each hold over 12,000 gallons of wine.

120. Right now what's in them is just grape juice and skins. 121. To convert the juice into wine, yeast is needed.

122. The yeast eats the sugar in the juice.

123. It turns the juice into alcohol.

124. More happens during fermentation than just making alcohol.

125. Alcohol extracts the red color.

126. Alcohol extracts the flavors that are stored in the grape skins. 
127. Once fermentation is complete, the wine is aged in oak barrels for about a year.

128. Mondavi will fill up over 6,500 of these barrels with his cabernet wine.

129. This year, some of the wine will be part of a barrel experiment.

130. There is a tradition of putting wine in oak barrels.

131. This tradition dates back to the wineries of old France. 132. Before stainless steel, oak barrels were the only good leakproof containers in which to ferment and store wine. 133. It is only recently that winemakers have started thinking of oak for its contribution to the wine's taste. 134. Oak increases the wines' complexity and adds a pleasant vanilla flavor.

135. Today, winemakers are very choosy about what oak they use.

136. Most agree that only wood from this particular forest in central France adds the right flavor to cabernet wine. 137. But now it turns out the techniques for making barrels may be even more important.

138. Francoise Frere is in the heart of Burgundy.

139. They have been making barrels for over a century.

140. The oak boards are heated up by the fire.

141. They become soft and flexible.

142. Strong cable is wrapped around the bottom of the barrel. 143. The cable is pulled tight. 
144. The boards bend easily into the right shape.

145. Metal rings hold the wood pieces in place.

146. Barrelmakers traditionally use heat to bend the oak without breaking it.

147. Winemakers believe the heat can also cause beneficial chemical changes in the wood that alter the oak flavors.

148. These flavors are transferred to the wine.

149. This barrel was burned a little too much.

150. The winemakers often ask for barrels that are toasted to

a nice dark brown.

151. At Mondavi they want to find out how much should a barrel be toasted if it's meant for cabernet wine.

152. This year they're taking a batch of cabernet and putting half of it into light barrels,

153. Half of it will go into dark ones.

154. Wines can be influenced by the environment.

155. Wines can be influenced by the sun.

156. Wines can be influenced by the choices man makes.

157. Including the containers, including the barrels.

158. They are subtle differences.

159. They can be profound.

160. If you add each of those subtle differences, one upon another, even if they're very minute, then you can end up with something special. 
161. Tim will have to wait awhile for results from the barrel experiment until the oak has finished changing the wine's flavor.

162. Now is the perfect time to taste some of his 300 other experiments from this year.

163. Today he's tasting wine from the two cabernet vineyard experiments.

164. In comparing the effects of shaded leaves versus shaded grapes, the shaded leaves produced the vegetable flavor, just as Janice Morrison predicted.

165. In a comparison between bushy vines and vines trained on vertical trellises, rearranging the vines didn't improve Tim's best cabernet.

166. Both of the wines are really terrific.

167. Tim definitely prefers $A$.

168. Tim is disappointed in having to say that because $A$ is the control lot, which is the normal, the more shaded lots. 169. It's possible the experiment was thrown off by the cool, dry, growing season this year.

170. Tim plans to repeat the experiment next year.

171. He's really not that disappointed.

172. Tim thinks every time they do an experiment, they learn more about what makes wine tick.

173. That helps them produce better wine. 
174. In the case where they get results that were different from what they expected, it forces them to develop an explanation that sometimes they weren't looking for.

175. It's more educational sometimes to learn something new, than to confirm something they knew already.

176. If all goes well, Mondavi will continue making discoveries about cabernet.

177. Watch out France, America is catching up. 
APPENDIX B

MACROPROPOSITIONS 
MACROPROPOSITIONS

1. Winemaking can be a matter of chance.

2. There may be more ways to make a great wine than most of his (Tim Mondavi's) colleagues think.

3. Napa Valley produces wine that nearly equals the very best from France.

4. Winemakers are influencing the taste of their wine in unprecedented ways.

5. At Mondavi, they're taking a systematic approach to achieving that symphony.

6. When the winemakers agree on what they like best, they try to figure out what makes a cabernet taste that way.

7. In France there has always been a strong belief that the plot of land is what determines how grapes and wine taste. 8. A belief that a winemaker can't do much in a vineyard other than to choose the right land.

9. The best wines seem to come from places where grapevines are small.

10. Here (at Mondavi) vines grow bushier than in France. 11. Tim has noticed his biggest vines produce cabernet grapes with a less pleasant balance of flavors. 12. The size of the vine might not be what really counts. 
13. Tim is concerned about the effect of the shade on some of the vineyards.

14. The cause of the vegetable taste may be the way the grapes get shaded on big bushy vines.

15. Grapes only manufacture all their potential fruit flavor when there is enough red light compared to other colors. 16. At Mondavi, there's an experiment to correct the light balance.

17. Leaves on the vertical trellis won't filter the light falling on the grapes.

18. Tim Mondavi tried a vertical trellis last year in his bushiest vineyard and got a dramatic reduction in vegetable flavor.

19. What he (Tim Mondavi) hopes to find is that they prefer the wine from the vertical trellising system because of the fruit.

20. A scientist with a different idea has an experiment here too.

21. In this experiment, they are trying to make the fruit taste worse.

22. Janice believes the major cause of vegetable flavor is shaded leaves, not shaded grapes.

23. The ideas is to show the vegetable flavor develops even though the grapes are getting plenty of red light. 
24. It's possible that shaded leaves are producing some compound that then moves into the grapes and causes this vegetative character.

25. Grape samples collected throughout the growing season have their juice analyzed to follow the development of sugars and acids.

26. To convert the juice into wine, yeast is needed.

27. Wine is aged in oak barrels for about a year.

28. The tradition of putting wine into oak barrels dates back to the wineries of old France.

29. It's only recently that winemakers have started thinking of oak for its contribution to the wine's taste.

30. The techniques for making barrels may be even more important.

31. Winemakers believe the heat can also cause beneficial changes in the wood that alter the oak flavors transferred to the wine.

32. Wines can be influenced by the environment, by the sun, the soil, the choices that man makes including the containers, including the barrels that are there.

33. The shaded leaves produced the most vegetable flavor.

34. Tim plans to repeat the experiment next year.

35. Tim thinks every time they do an experiment, they learn more about what makes wine tick and that helps them produce a better wine. 
APPENDIX C

SAMPLE RECALLS 
83

Wine making

Introductory Vocabulary

(v)

1. Napa Valley - a wine making region inCallfornia

qI

2. Monday - the name of the winery, the name of the winemaker

3. vineyard - the place grapes are grown for wine

4. barrel - a large, round container

$1 E$

5. trellis - a light, upright, wooden framework used as a support for

$3^{\mu}$ climbing plants

Directions

Do not take notes. After you have seen or heard the tape twice, write as many facts as you can.

Examples 1. Nape Valley is th California.

2. Mondarl to the name of the winery.

I1. The weather of Napa Valley is good for wine production.

I 11. Napa tallage grape tree are taller ilia ones in France.

1. The tree leaves shut dow r the rod lifer.

- Burned and not burned bairale make urine different taste.

- Good wince's grapes are rot good taille to eat.

1. Grape juror and cast tic mixed to make wine.

- Calformia ir catching up to France

1- Here are a lar of vineyard in Napa County.

1 - They be rd leaves to cover grapes from sunshine. 
84

Wine making

Introductory Vocabulary

(P)

1. Napa Valley - a winemaking region in California

2. Monday - the name of the winery, the name of the winemaker

3. Vineyard - the place grapes are grown for wine

$8-1$

4. barrel - a large, round container

5. trellis - a light, upright, wooden framework used as a support for

$4-D$ climbing plants

$+M$

Directions:

twat

Do not take notes. After you here seen or heard the tape twice, write as many facts as you can.

Example: 1. Napa Valley is in California.

2. Mondavi is the name of the winery.

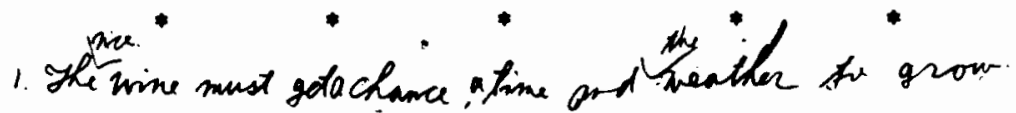

The nine is produced fy mature.

The tarred makes tines text.

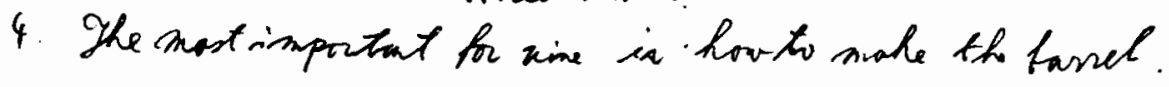

115 The formal is made of oak.

1 16. Leaves are like a filter.

7. These leaver me more important st om gamp.

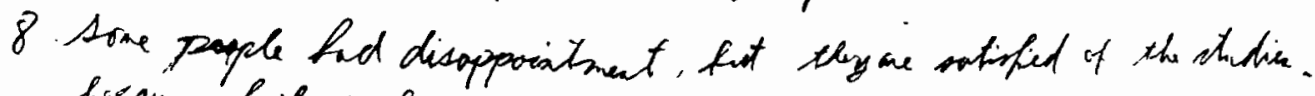

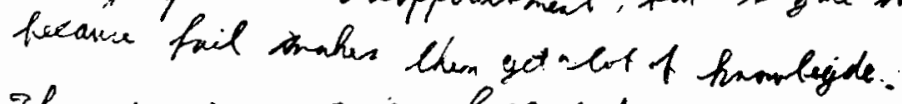

9. They diseded about half of the in light and the then in dark.

10 It ser. like game in vert place to grow. 


\section{Winemaking}

Introductory Vocabulary

1. Napa Valley - a winemaking region in California

2. Mondavi - the name of the winery, the name of the winemaker

3. Vineyard - the place grapes are grown for wine

4. barrel - a large, round container

5. trellis - A High, upright, wooden framework used as a apport for climbing plants

\section{Directions:}

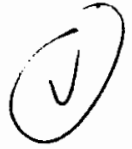

Do not take notes. After you have seen or heard the tupe twice, write os many facts as you can.

Example: 1. Napa Valley is in Calffornie.

2. Mondavi is the name of the winery.

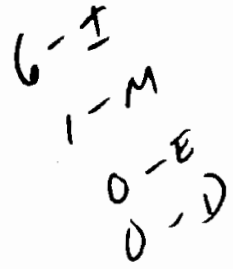

1 Imondari is good place to mathe vime and very large

1 They compane grapes groum in shade wiok ones on oun I Theig teat a tacte of wine

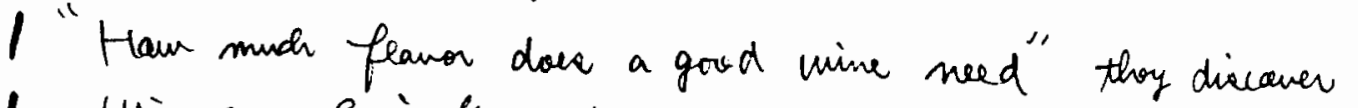
1 Wine can the inferenced tey cunny: flavor.. and co on 
86

Wine making

Introductory Vocabulary

(A)

1. Napa Valley - a wine making region in California

91

2. Monday - the name of the winery, the name of the winemaker

3. vineyard - the place grapes are grown for wine

$2^{D}$

4. barrel - a large, round container

$3 \mu$

5. trellis - a light, upright, wooden framework used as a support for climbing plants

Directions:

Do not take notes. After you have seen or heard the tape twice, write as many facts as you can.

Example: 1. Napa Valley is in California.

2. Mondavi is the ma me of the winery.

1. wine making is natural, we cain no f do much about it.

I III a. Wimrmaking depends on soil, calamite, weatheryeved the contuses.

v. In Tape Valley the sail is rich, the weather, so they make good

Wins.

115 In laps Valley the make almost as good wine as the Fraise do.

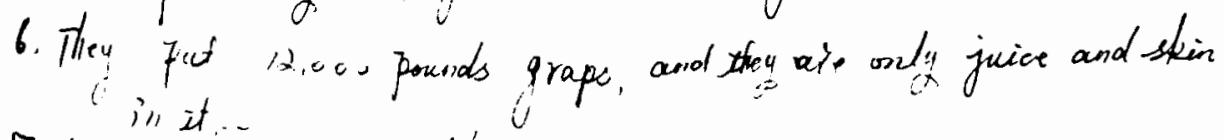

117 loves of grapes also inf louse the Jat of wine.

8. flavin aspacons also grow: Na fo Valley.

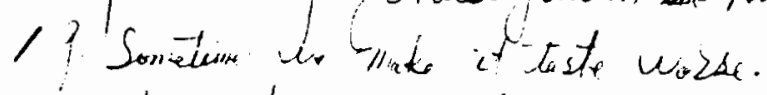

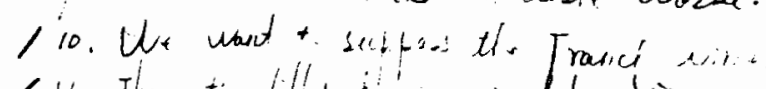

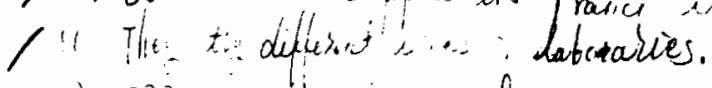

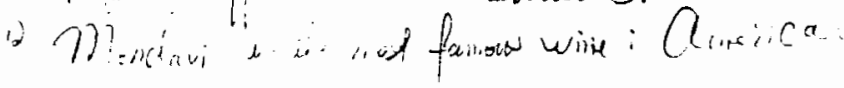

